\title{
The Circular Carbon Economy Index 2021 - Results
}

Mari Luomi, Fatih Yilmaz,

Thamir Alshehri 


\section{Acknowledgments}

The authors are extremely grateful to all experts, stakeholders and data providers who contributed in various ways to this project. This included sharing data, clarifying dataset and indicator methodologies, discussing concepts and metrics, providing insights from different country contexts, exchanging views on the best ways to measure the various dimensions of the index, validating the results, developing the index web portal, and helping with the publications, events and outreach related to the index.

These individuals include Dr. Anvita Arora, Dr. Fahad Alturki, Dr. Frank Felder, Fahad Alajlan, Dr. Gasem Fallatah and his team, Ahmed Al-Zahrani, Amar Amarnath, Pavithra Kumar Shetty, and Alaa Alarfaj from KAPSARC's Energy Information Management program, colleagues at KAPSARC's Climate and Environment, Energy Transitions and Electric Power, Markets and Industrial Development, Library, Events and Communications teams, and speakers and participants at the KAPSARC stakeholder engagement workshop for the CCE Index (June 6, 2021).

We also met and exchanged emails with dozens of other experts and data providers. We are particularly thankful to the experts and data providers at BloombergNEF, EY, the Global CCS Institute and the World Intellectual Property Organization for sharing additional data and advising on imputations.

We wish to extend a special thanks to the members of the CCE Index International Technical Advisory Committee members:

Dr. Christopher Consoli, Global Carbon Capture and Storage Institute

Prof. Jorge Gascon, King Abdullah University of Science and Technology

Yoshikazu Kobayashi, The Institute of Energy Economics, Japan

Dr. Coby van der Linde, Clingendael International Energy Programme

Dr. Anupama Sen, Oxford Institute for Energy Studies

\section{About KAPSARC}

The King Abdullah Petroleum Studies and Research Center (KAPSARC) is a non-profit global institution dedicated to independent research into energy economics, policy, technology and the environment across all types of energy. KAPSARC's mandate is to advance the understanding of energy challenges and opportunities facing the world today and tomorrow, through unbiased, independent, and high-caliber research for the benefit of society. KAPSARC is located in Riyadh, Saudi Arabia.

This publication is also available in Arabic.

\section{Legal Notice}

(C) Copyright 2021 King Abdullah Petroleum Studies and Research Center ("KAPSARC").

This Document (and any information, data or materials contained therein) (the

"Document") shall not be used without the proper attribution to KAPSARC. The

Document shall not be reproduced, in whole or in part, without the written permission of KAPSARC. KAPSARC makes no warranty, representation or undertaking whether expressed or implied, nor does it assume any legal liability, whether direct or indirect, or responsibility for the accuracy, completeness, or usefulness of any information that is contained in the Document. Nothing in the Document constitutes or shall be implied to constitute advice, recommendation or option. The views and opinions expressed in this publication are those of the authors and do not necessarily reflect the official views or position of KAPSARC. 


\section{Executive summary and key messages}

here is an urgent need to align global carbon dioxide and other greenhouse gas emissions with climate-safe trajectories. A broad range of technologies and approaches are needed to achieve this cost-effectively and equitably. The circular carbon economy (CCE) concept provides a holistic, flexible and pragmatic framework for countries to plan their respective contributions toward the commonly agreed climate goals.The CCE builds on the concept of the circular economy, with two important distinctions: it has an exclusive focus on energy and emissions, and it adds a fourth pillar to the three pillars of the circular economy: reduce, reuse, recycle, and remove. The fundamental goal of the CCE is to prevent atmospheric carbon dioxide and other GHG emissions. In addition, the CCE approach emphasizes economic incentives and benefits associated with managing carbon and the need to focus on the most cost-effective mitigation solutions.

The CCE Index, which has been developed by KAPSARC and is now launched in its first edition, is intended as a tool for governments and other climate change policy stakeholders to evaluate progress in support of domestic planning and decision making in the nexus of energy, emissions, and the economy. It enables data-driven discussions and comparisons across countries around questions including:

How is a country engaging with the main climate change mitigation options and technologies in terms of depth and diversity compared to others?

How is a country positioned to accelerate progress toward a CCE compared to others? How strong are its related enabling frameworks in areas including policy, technology, finance, business environments and energy security?
How are different regions and countries that are at different stages of economic development performing on the CCE today, and how much potential do they have to accelerate their transitions toward the CCE?

How are the world's major oil-producing countries managing carbon circularity and preparing their oil and gas sectors and related industries for CCE transitions?

The 2021 CCE Index compares 30 major economies on two temporal dimensions: current $\mathrm{CCE}$ performance and CCE potential. The following highlevel messages stand out:

1. No single country has yet achieved a circular carbon economy, in which atmospheric carbon dioxide and other greenhouse gas emissions are minimized and circulated throughout the economy, where possible, to generate value.

There are significant differences between the top performers, which are high-income industrialized countries, and the lowest performers, which are middle-income countries with high levels of economic reliance on oil exports.

2. The top three countries in the $2021 \mathrm{CCE}$ Index, Norway, the United Kingdom and Germany, receive the highest scores on both the Performance and Enablers sub-indices. This means that they both display the highest level of engagement with a broad variety of CCE activities, such as renewable energy deployment or carbon capture and storage or hydrogen projects, and they are the best positioned to keep making further progress toward carbon circularity. 
3. In the area of CCE Performance, the greatest contribution to countries' scores, on average, comes from energy efficiency, and renewables and electrification. However, there are significant differences among individual countries. Most countries are making progress in switching away from high-carbon intensity fuels in the power sector. Performance is less even in areas requiring either access to technology (nuclear energy) or capacity to invest in new technologies (hydrogen and carbon capture and storage). Countries also show varying rates of success in conserving their existing forest resources.

4. In the area of CCE Enablers, technology, knowledge and innovation gaps and lack of access to CCE finance are the biggest obstacles faced by countries to accelerating their progress toward CCE. While many developed economies have been advancing on clean technology deployment, progress in emerging and developing countries in creating, diffusing and absorbing the required knowledge has been more limited. Similarly, many countries are facing challenges in leveraging sustainable finance, partly because of the low institutionalization of the necessary regulatory frameworks. While progress in policy and regulatory enablers for the CCE is less uneven across countries, gaps continue to exist, and all countries need to step up their efforts to reach carbon circularity within the agreed global timeframes.

\section{Gauging how the world's largest oil} producers manage their oil sectors and related industries is also crucial, given the extent of the circularity transition ahead of them. An additional Oil Producers Lens score measures related opportunities and challenges. The Performance score here shows that some countries in this group rise in rank compared to their peers when carbon management in the sector is considered. On the enablers side, countries' potential to make progress toward a CCE appears to improve as their reliance on oil export revenues decreases - albeit this correlation does not necessarily imply a causal relationship.

The CCE Index is first and foremost intended as a tool to promote country-level, data-driven discussions on policy priorities and national strengths and weaknesses related to implementation. Close examinations of the various indicators used in the index can spur discussions to identify more appropriate CCE metrics for specific country or sub-national contexts. Gaps in data can alert data stakeholders to strive to make data available, or to develop new ways to measure CCE performance and potential at the country level. Finally, while the primary purpose of the CCE Index is not to rank countries, it allows for comparisons, both in a global context and in different reference groups. For countries facing challenges with performance or enablers, the index can help pinpoint areas where support is needed, including from international partners.

This first edition of the CCE Index is also intended as a conversation starter for identifying the optimal ways of measuring CCE performance and enablers across countries. The CCE Index will be updated and expanded annually, and future editions will be revised to include additional countries, indicators, improved and updated datasets, and new ways of measuring CCE performance and transition enablers. The first edition of the CCE Index is therefore also put forward as an invitation to contribute to further developing this "new language of carbon"1 by helping KAPSARC further refine the index to serve a growing number of countries and contexts with the best possible indicators and metrics. 
here is an urgent need to align global carbon dioxide and other greenhouse gas (GHG) emissions with climate-safe trajectories. The Paris Agreement sets the globally agreed goals for this: keeping the average global temperature increase to well below 2 degrees Celsius above preindustrial levels, while pursuing efforts to limit the increase to 1.5 degrees; reaching a peak in global GHG emissions as soon as possible; and achieving emissions neutrality in the second half of the century (UNFCCC 2015). A broad range of technologies and approaches are needed to achieve these goals, and each country will apply a different mix of these technologies. The circular carbon economy (CCE) concept provides a holistic, adaptable and pragmatic framework for this purpose, and the CCE Index, developed by KAPSARC, offers a tool that builds on this framework to develop indicators and metrics to support related, data-driven policy discussions.

This KAPSARC Discussion Paper presents an analysis and interpretation of the 2021 CCE Index results. A detailed description of the methodology is presented in the KAPSARC Discussion Paper, "The Circular Carbon Economy Index 2021 Methodology" (Luomi, Yilmaz and Alshehri 2021). The full 2021 CCE Index results are available on the CCE Index web portal: https://cceindex.kapsarc.org.

\section{The CCE concept}

The CCE approach provides a holistic, flexible and pragmatic framework for countries to plan and implement their respective contributions toward the Paris Agreement goals. By assessing all available mitigation options side by side, it helps countries maximize their emissions reduction and management potential. It also helps to ensure cost-effectiveness and equity by encouraging them to play to their strengths - whether renewable energy, hydrocarbons with carbon removal, or nature-based solutions. Adopting a CCE approach to managing emissions also helps pinpoint areas where the implementation of existing technologies and approaches needs to be accelerated, and where more attention to enablers is needed to bring new technologies to market.

The CCE builds on the concept of the circular economy, with two important distinctions: it has an exclusive focus on energy and emissions (instead of materials, products and waste), and it adds a fourth pillar to the three pillars of the circular economy: reduce, reuse, recycle, and remove. The fundamental goal of the CCE is to prevent atmospheric carbon dioxide and other greenhouse gas emissions through these four pillars, which include reducing emissions through energy efficiency and renewable energy, recycling carbon through bioenergy, reusing carbon by converting it into materials such as polymers or concrete, and removing carbon dioxide from the atmosphere through carbon capture and storage and natural sinks.

Figure 1 shows the main CCE activities organized under the four Rs of the CCE, along with crosscutting activities, which contribute to, or enable, one or more Rs. The classification follows the taxonomy developed and used commonly by KAPSARC researchers and international organizations in a series of CCE guides (see https:// www.cceguide.org/) (for other taxonomies, see Luomi, Yilmaz and Alshehri [2021]). 
Figure 1. The circular carbon economy

\section{RE D UCE}

\section{Energy efficiency}

\section{Non-bio renewables}

\section{Nuclear energy}

Fuel switching to lower-carbon fuels

\section{RECYCLE}

\section{Bioenergy}

Fuel switching to bioenergy

Carbon capture and storage (incl. enhanced oil recovery)

Direct air capture

\section{Electrification}

Green and blue hydrogen

Natural sinks

REMOVE

Carbon capture and utilization

Natural sinks

RE U S E 
The CCE approach also emphasizes economic incentives and benefits associated with managing carbon. This includes converting it into products that bind carbon over long periods of time, and the need to focus on the most cost-effective mitigation solutions in each country and context (for an expanded conceptual discussion, see e.g., Luomi et al. [2021]). These aspects are particularly important for countries with sizable hydrocarbon and related energy-intensive industries, given the scale and cost of the transformation still ahead for these harder-toabate sectors. Here, the CCE expands the 'solution space' by drawing attention to carbon circularity options both for these countries and more generally for hard-to-abate sectors worldwide.

\section{The CCE Index}

The CCE Index aims to measure countries' progress in and potential for reaching circular carbon economies. It is a composite indicator comprised of a total of 47 individual variables or indicators. When aggregated together, these provide insights into how well countries are performing on these two temporal dimensions of the CCE compared to each other. The 2021 edition includes 30 countries: the 19 Group of Twenty (G20) member countries and 19 major global oil producers. $^{2}$

The CCE Index has two sub-indices: one for measuring countries' current performance on the various CCE activities and the other for gauging how countries are positioned to make progress toward the CCE, based on key enabling factors. The CCE
Index also allows for additional comparisons among top oil-producing countries through a separate set of add-on indicators called the Oil Producers Lens, which helps estimate how these countries' industrial performance and business environments are aligning with the CCE.

Each country receives a score on a scale of $0-100$ for each indicator and for the total index and its sub-indices and lenses. Separate scores are first calculated for the sub-index scores, which are then aggregated to form the total CCE Index score. In total, the CCE Index therefore consists of three aggregate scores: the CCE Performance score, the CCE Enablers score, and the total CCE Index score. Ten oil-producer-specific indicators, referred to as the Oil Producers Lens, are applied to the 19 oil-producing countries to form additional three scores: the Oil Producers Lens Performance score, the Oil Producers Lens Enablers score, and the Oil Producers Lens total score. ${ }^{3}$

A country's score should be interpreted as an indication of how close it is to ideal performance, either compared to its top-ranking peers or a technical optimum. For example, a score of 66 would be equivalent to two-thirds of a potential maximum score. The CCE Index also provides a rank for each country at the index and sub-index levels to facilitate comparisons across countries (see Appendix 1).

Figure 2 presents the 2021 CCE Index indicator framework. 
Figure 2. 2021 CCE Index indicator framework

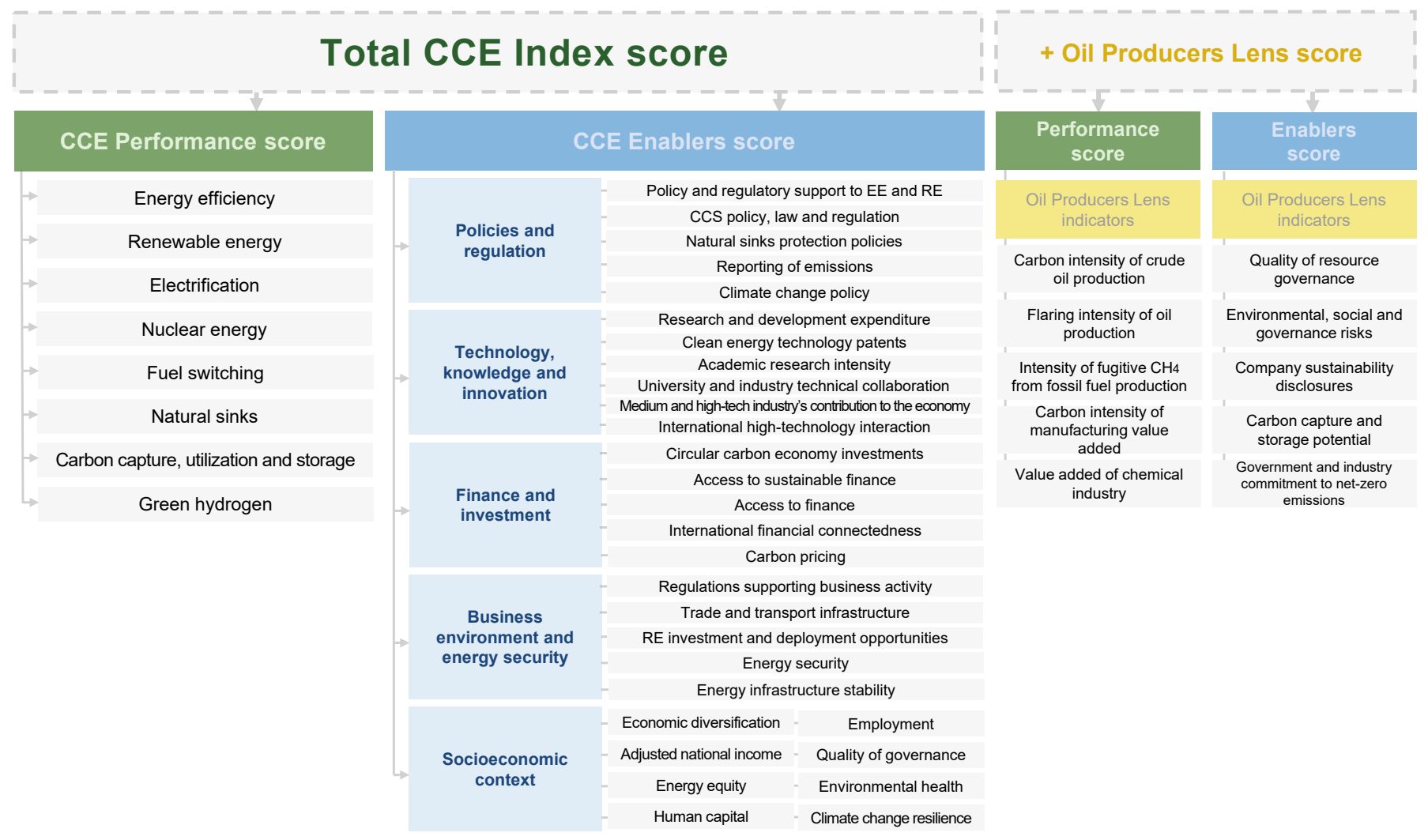

Source: Authors.

Each of the two sub-indices and the add-on lens for oil producers are intended to promote various types of data-oriented discussions. There are four main questions that the CCE Index is designed to answer:

Total CCE Index score: How are countries overall handling the transition to the CCE, and is their current performance on par with their future potential?

CCE Performance score: How are countries performing presently on the different CCE activities, including crosscutting ones, and how diverse are the CCE activities countries engage in?
CCE Enablers score: How are countries positioned to unlock their CCE potential, building on key enabling factors such as policy, technology, finance, and enabling business environments?

Oil Producers Lens: How well are major oilproducing countries managing carbon circularity and value creation in their oil and gas and related industries? How well are these industries positioned for a carbon-neutral future? 


\section{CCE Index results}

his section presents and analyzes the results of the 2021 CCE Index. It first presents the total CCE Index scores and the scores for its sub-indices and sub-dimensions, as well as those for the Oil Producers Lens. It also gives examples of how examining countries in different groups, such as regions or incomebased groups, can allow for more meaningful comparisons and better-contextualized data and policy discussions.

The high-level 2021 CCE Index scores are presented in Appendix 1. The scores and rankings, the full underlying datasets used in the index, and a 'codebook' containing detailed information about each indicator are available via the CCE Index web portal: https://cceindex.kapsarc.org.

\section{Scores and rankings}

\section{Total CCE Index scores}

The CCE total Index score is calculated as a simple average of the CCE Performance and CCE Enablers scores. Countries achieving the highest scores on both sub-indices therefore receive the highest ranks: If a country is both performing well at present and has high potential to keep improving in the future, it achieves a high total score. The top three countries in the 2021 CCE Index are Norway (68), the United Kingdom (65) and Germany (64). These countries demonstrate the highest levels of engagement with a broad variety of CCE activities, such as renewable energy shares in the energy mix, hydrogen or carbon capture and storage projects, and their high scores on the enabling factors make them the best-placed out of the 30 countries to keep making further progress toward carbon circularity. At the tail end are Iraq, Nigeria, and Algeria, which on average score 42 points less than the top-three countries. (See Figure 3.)

On average, countries' Performance scores are lower than their Enablers scores (34 and 46, respectively). This means that, for most countries, the Enablers sub-index accounts for a higher share of their total score. Four countries have a higher Performance score than their Enablers score: Brazil, Saudi Arabia, Angola and Iraq (see Figure 3 and Box 1).

Figure 3. Total 2021 CCE Index scores and proportional sub-index contributions

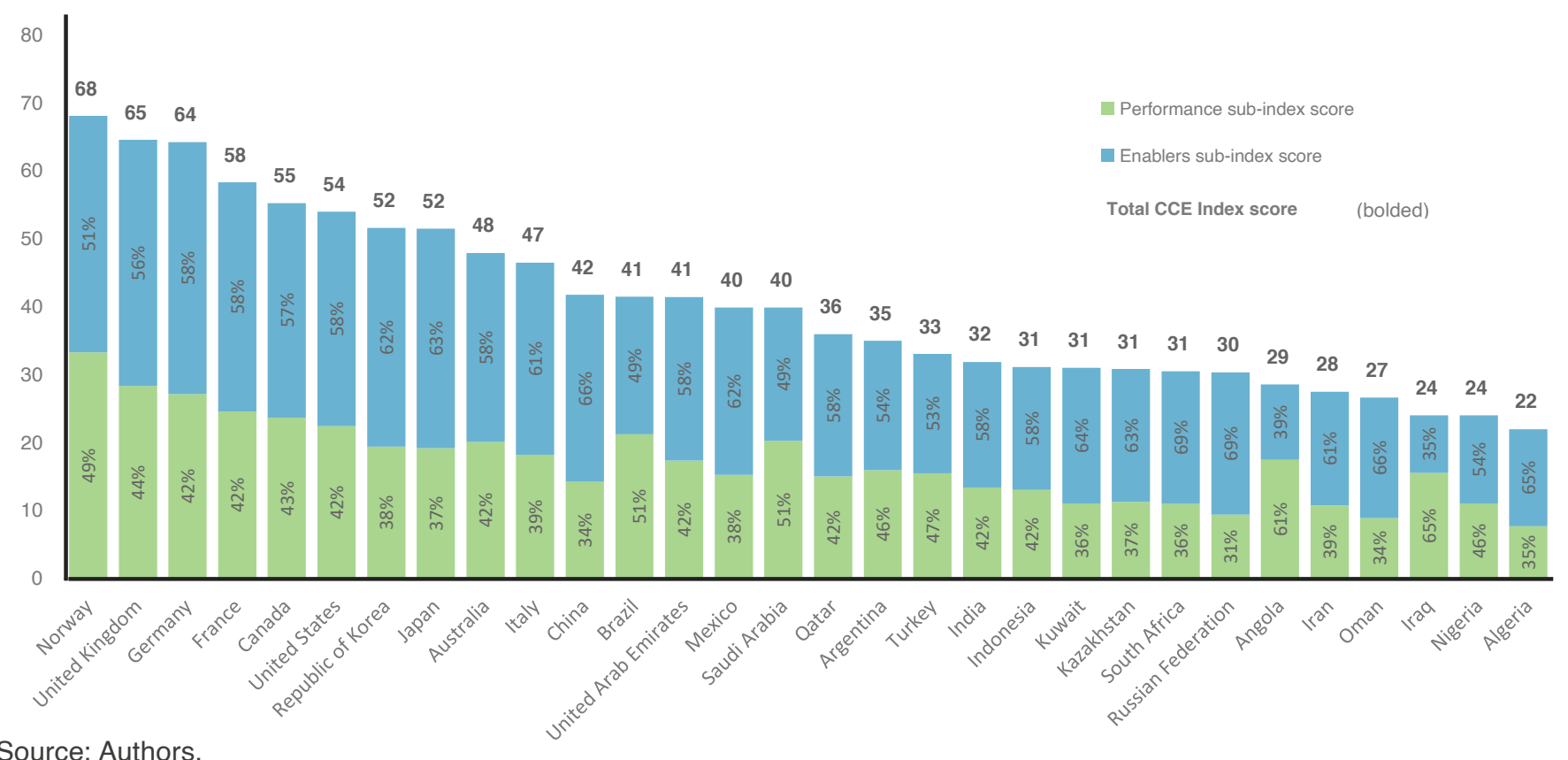

Source: Authors 
Box 1. Comparison of CCE Performance and Enablers scores

Another way to examine the relationship between the two scores is to compare them to the average country scores on each sub-index. Most countries with a score above the Performance average (34) also have a score above the Enablers average (46). Some countries with higher Enablers scores than their Performance scores, such as Japan, the Republic of Korea, China and Russia, can be characterized as having unmet CCE potential. Countries with higher Performance scores compared to their Enablers scores may either have uneven performance across the different Enablers sub-dimensions (such as Brazil and Saudi Arabia), or they score low across all Enablers sub-dimensions but score higher than average on some CCE activities under the Performance sub-index (for example Angola and Iraq) (see Appendix 1).

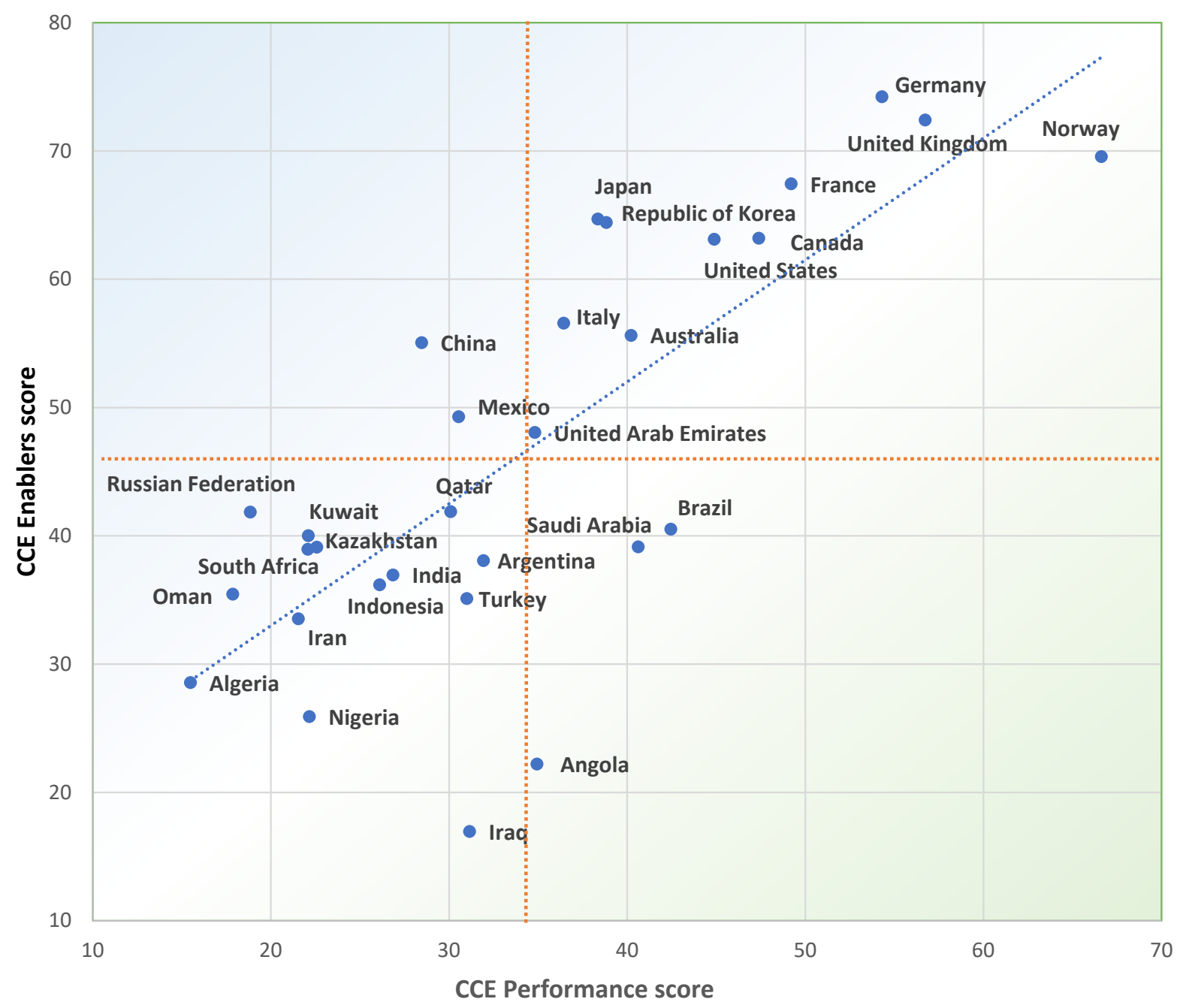

Source: Authors.

Key: red dotted lines $=$ average values; blue dotted line $=$ trend line. While both scores are between 0-100 by design, the figure zooms into actual scores. 


\section{CCE Index Performance scores}

$\mathbf{T}$

The Performance sub-index measures both the depth and breadth of countries' engagement on eight CCE activities: energy efficiency; renewable energy; electrification (which acts as a control variable for commercial variables) ${ }^{4}$; nuclear energy; fuel switching in the power sector (away from coal and oil); natural sinks; carbon capture, utilization and storage (which also captures blue hydrogen projects); and green hydrogen. Countries are rewarded both for strong performance on these activities and for the variety of activities they engage in.

The top-six countries in the 2021 CCE Performance sub-index also rank the highest in the overall CCE Index. There is significant variation in the scores across the countries: the average Performance score of the top three countries, Norway, the United Kingdom and Germany, is 42 points higher than that of the lowest three performers, Russia, Oman and Algeria. In general, higher-performing countries receive high scores on at least three, four or five different CCE activities (see Figure 4).

In terms of the relative contributions of individual CCE activities to country scores, the greatest contributions, on average, come from renewables and electrification (34\%) and energy efficiency (22\%). However, there are significant differences among individual countries, which reflects the spirit of the CCE, namely that different countries will advance toward carbon circularity through different routes. Most countries are making progress in switching away from high-carbon intensity fuels in the power sector. Performance is more uneven in areas requiring either access to technology (nuclear energy) or capacity to invest in new technologies (hydrogen and carbon capture and storage).

Countries also show varying rates of success in conserving their existing forest resources (see also Box 2).

Figure 4. 2021 CCE Performance scores and proportional indicator contributions

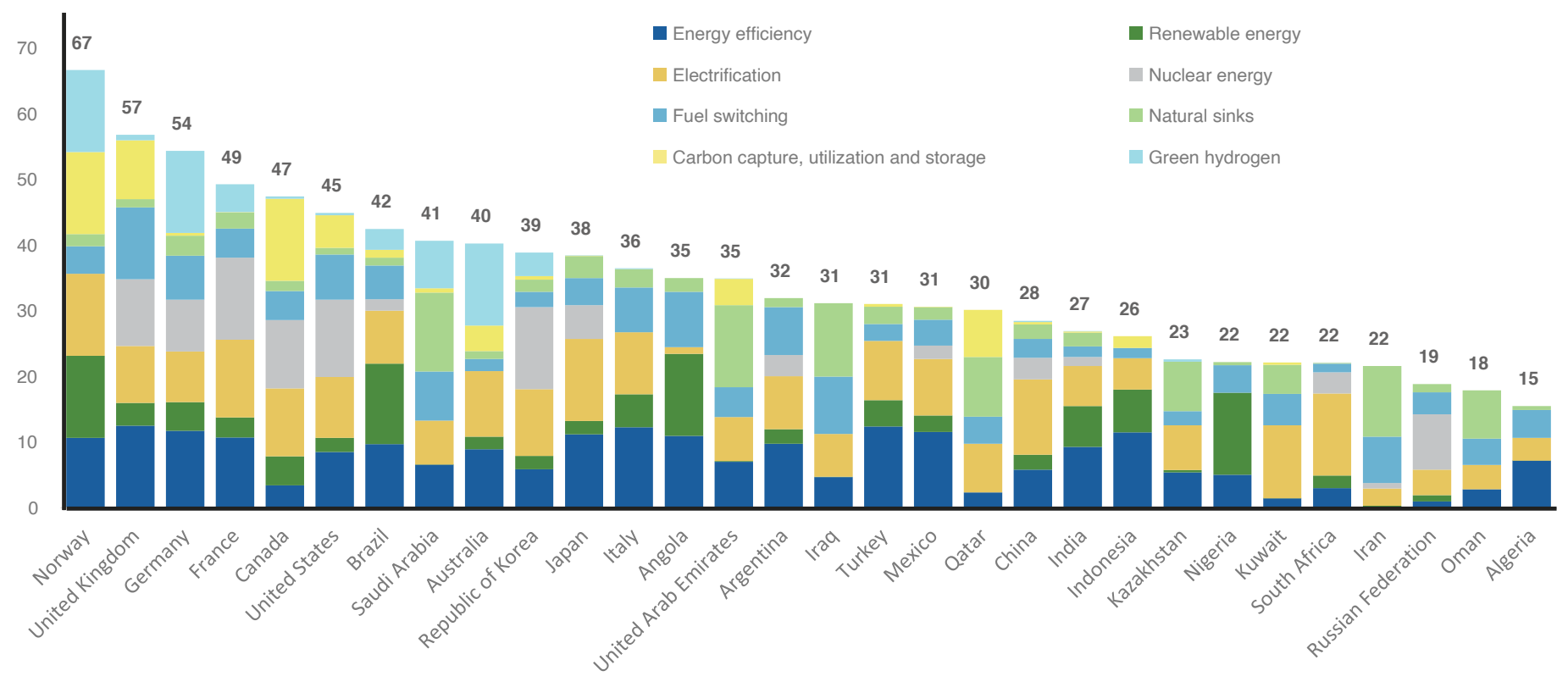

Source: Authors. 
Box 2. Comparison of the carbon intensity of gross domestic product (GDP) and 2021 CCE Performance scores

Does the CCE Performance sub-index measure what it is intended to measure? The carbon intensity of the economies included in the index is an evident proxy for testing whether the CCE Performance scores measure carbon circularity in the economy. The figure below shows the correlation between these two variables, $75 \%$, which is both statistically significant and magnitudally important. Generally, the higher the CCE Performance score a country has, the lower its carbon intensity.

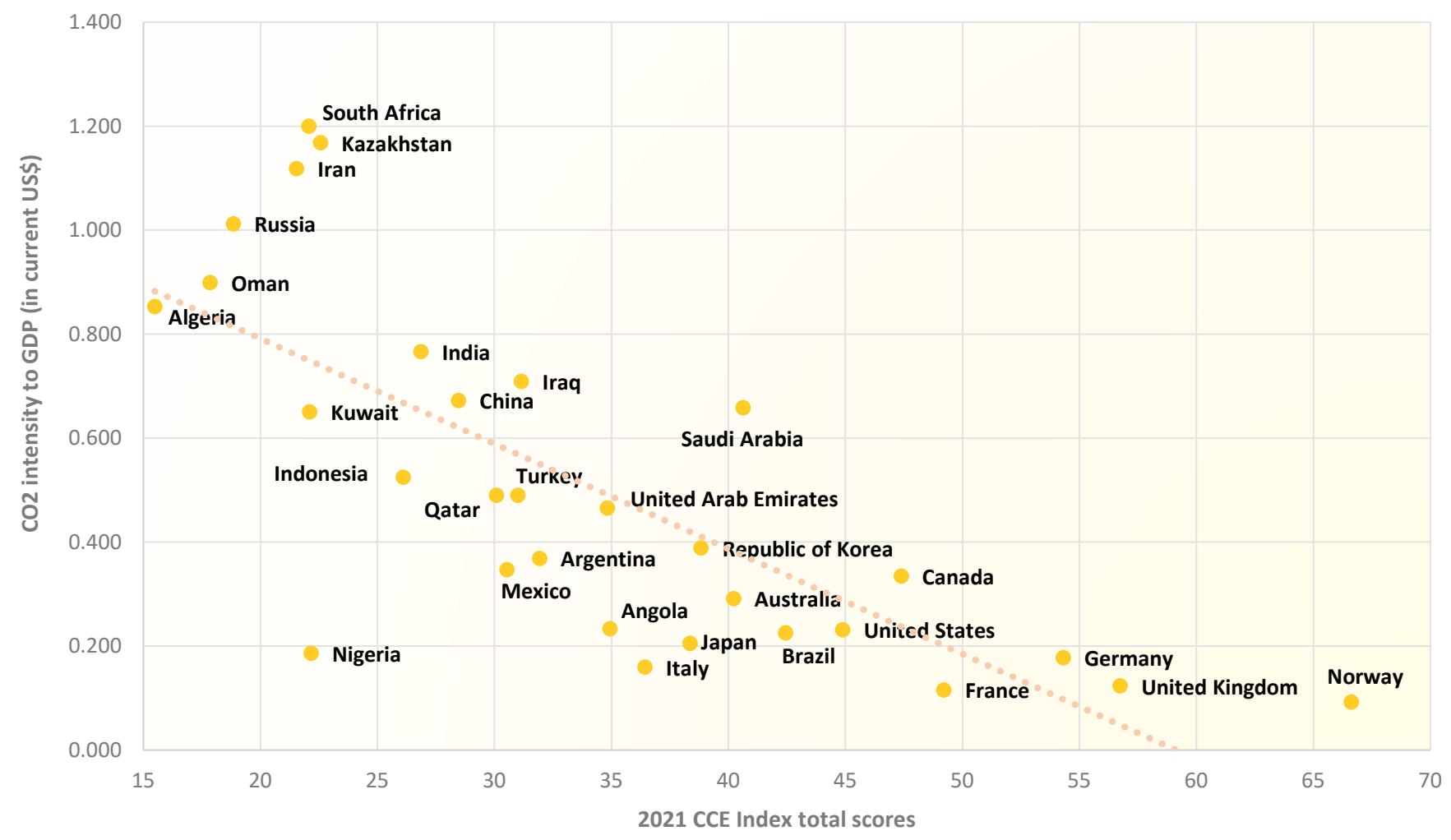

Sources: Authors' calculation from the CCE Index 2021 and Enerdata (2021).

Notes: Based on $\mathrm{CO} 2$ emissions from fuel combustion (sectoral approach). 


\section{CCE Index Enablers scores}

The CCE Enablers score measures countries' standing on five key 'sub-dimensions' that can enable and accelerate CCE transitions. These five areas are policies and regulation; technology, knowledge and innovation; finance and investment; business environment and energy security; and socioeconomic context. Higher scores in these dimensions are intended to indicate that a country is better positioned toward reaching emissions neutrality. Figure 5 presents the 2021 CCE Enablers scores, along with the contributions of each five key sub-dimension.

The three top-ranking countries in this sub-index are Germany, the United Kingdom and Norway, while Nigeria, Angola and Iraq score the lowest. More than half of the countries (17) are below the average score (47). The score range also indicates significant differentials across the countries, especially between the highest- and lowest-ranking countries. The average score of the top three countries is roughly three times the average score of the bottom three. In other words, sizable gaps exist in the strength of the enabling factors across countries, and reducing these gaps could significantly contribute to helping them realize their net-zero or emissions neutrality ambitions.

A closer look at the sub-dimensions is useful to identify relatively larger and potentially more critical gaps across countries on the 28 different enabler indicators. These indicators are divided across the five sub-dimensions that together are crucial for accelerating CCE transitions.
Policies and regulation play a crucial role in guiding both public and private actors toward a common goal, such as emissions targets. This dimension captures policies and regulation relevant to the different CCE activities, as well as addressing emissions more broadly. These include support for renewables, energy efficiency, carbon capture and storage, and emissions reporting.

In this dimension, the score distribution is less skewed across the countries compared to other dimensions (see Figure 5). Even though 17 countries score below the average (48), the difference between the top and bottom three ranked country score averages is 3.4 times. This implies, on the one hand, that countries are introducing policies to better position themselves in the current energy transition but, on the other hand, that significant gaps in this area exist in many countries (see Figure 6).

The top three countries are the United Kingdom, Germany and Italy, while the bottom three ranked countries are Angola, Oman and Iraq. Of the indicators under this dimension, carbon capture and storage law and regulation and climate change policy appear to be dominant drivers of countries' standing. Scores for policy support for renewables and energy efficiency are more even across countries, and generally higher than in other indicators in this dimension. While some countries, such as China, need significant improvements in their natural sink policies, several countries have strong stands in this area. There appears to be room for improvement in natural sinks protection policies in countries such as China, Oman and Kazakhstan, and in reporting emissions to the United Nations in countries such as Qatar, Iraq and Angola. 
Figure 5. 2021 CCE Enablers scores and proportional sub-dimension contributions

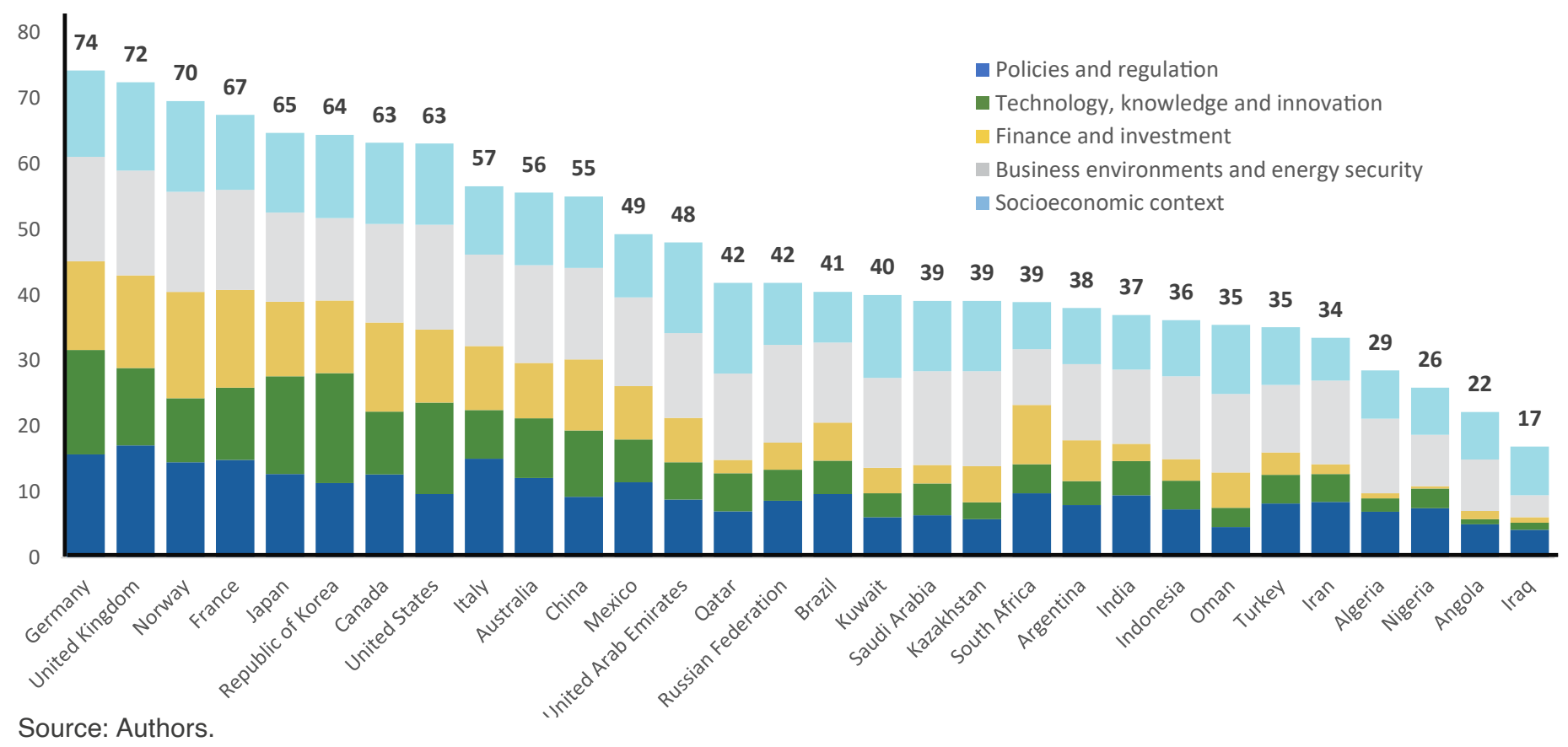

Figure 6. 2021 CCE Enablers - Policies and regulation sub-dimension

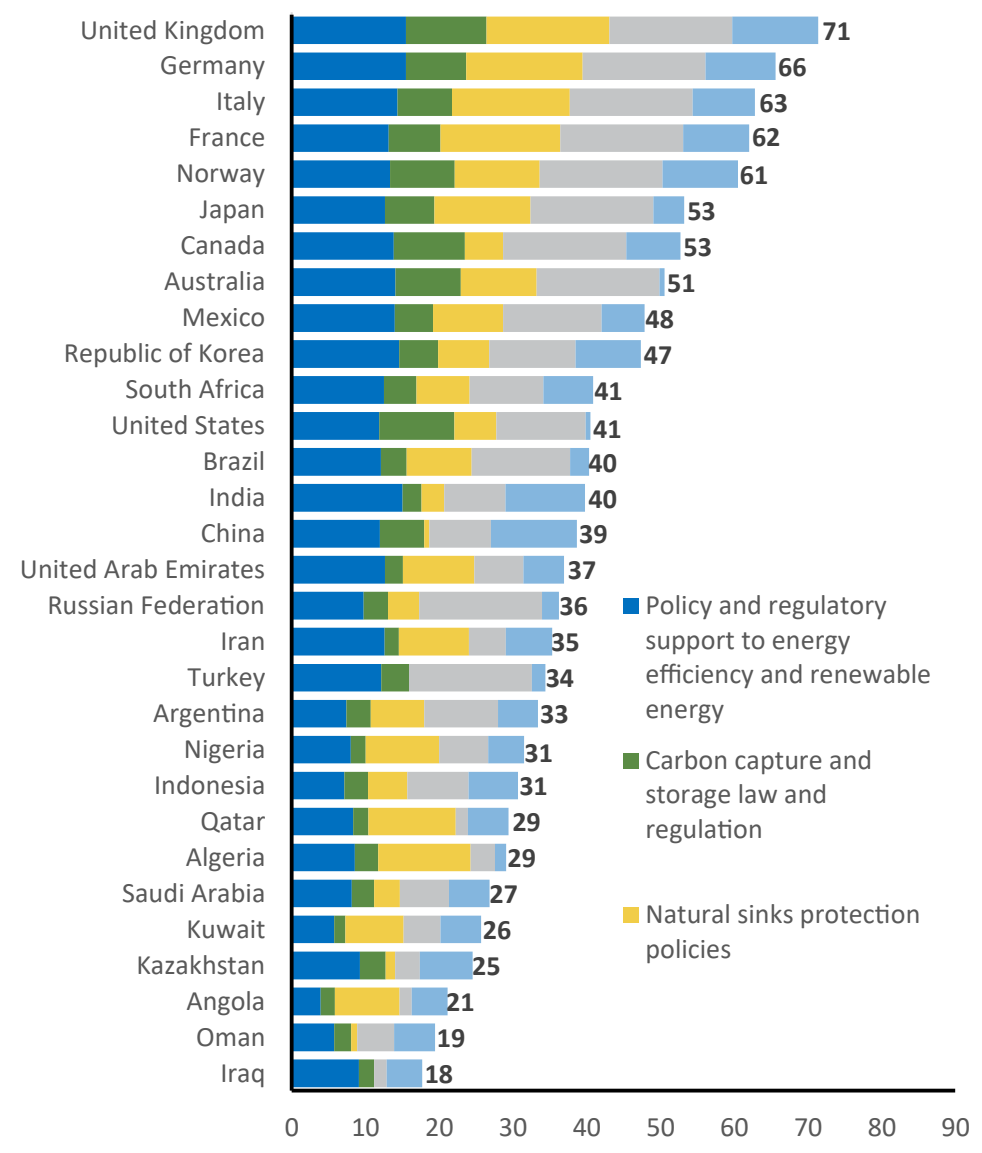

Source: Authors. 


\section{Technology, knowledge and innovation} captures countries' progress on the creation, distribution and absorption of relevant knowledge to unlock their CCE transition potential.

Considering that many clean technologies are still at the research and development (R\&D) stage, they have enormous potential to accelerate the global energy transition through supporting breakthrough technologies.

However, as Figure 5 shows, the gaps among the 30 countries under this dimension are the largest of the five Enablers sub-dimensions: 19 countries rank below the average Technology, knowledge and innovation score (34). The Republic of Korea records the highest score, followed by Germany and Japan. Algeria, Iraq and Angola have the lowest three scores (see Figure 7). The difference between the top and bottom three ranked country averages is 12 times, and, more importantly, the decline in the score distribution is noticeably rapid. These results indicate the existence of significant technology gaps, particularly in knowledge creationrelated indicators, namely $R \& D$ expenditure, clean energy technology patents and academic research intensity. Additionally, international high-technology interaction (i.e., knowledge diffusion and absorption through technology exports and imports) appears particularly limited in many countries below the average score. Finally, domestic technology interaction-related indicators (i.e., university-industry research collaboration, and medium- and hightechnology industries' contribution to the economy) are more evenly scaled across most countries.

Figure 7. 2021 CCE Enablers - Technology, knowledge and innovation sub-dimension

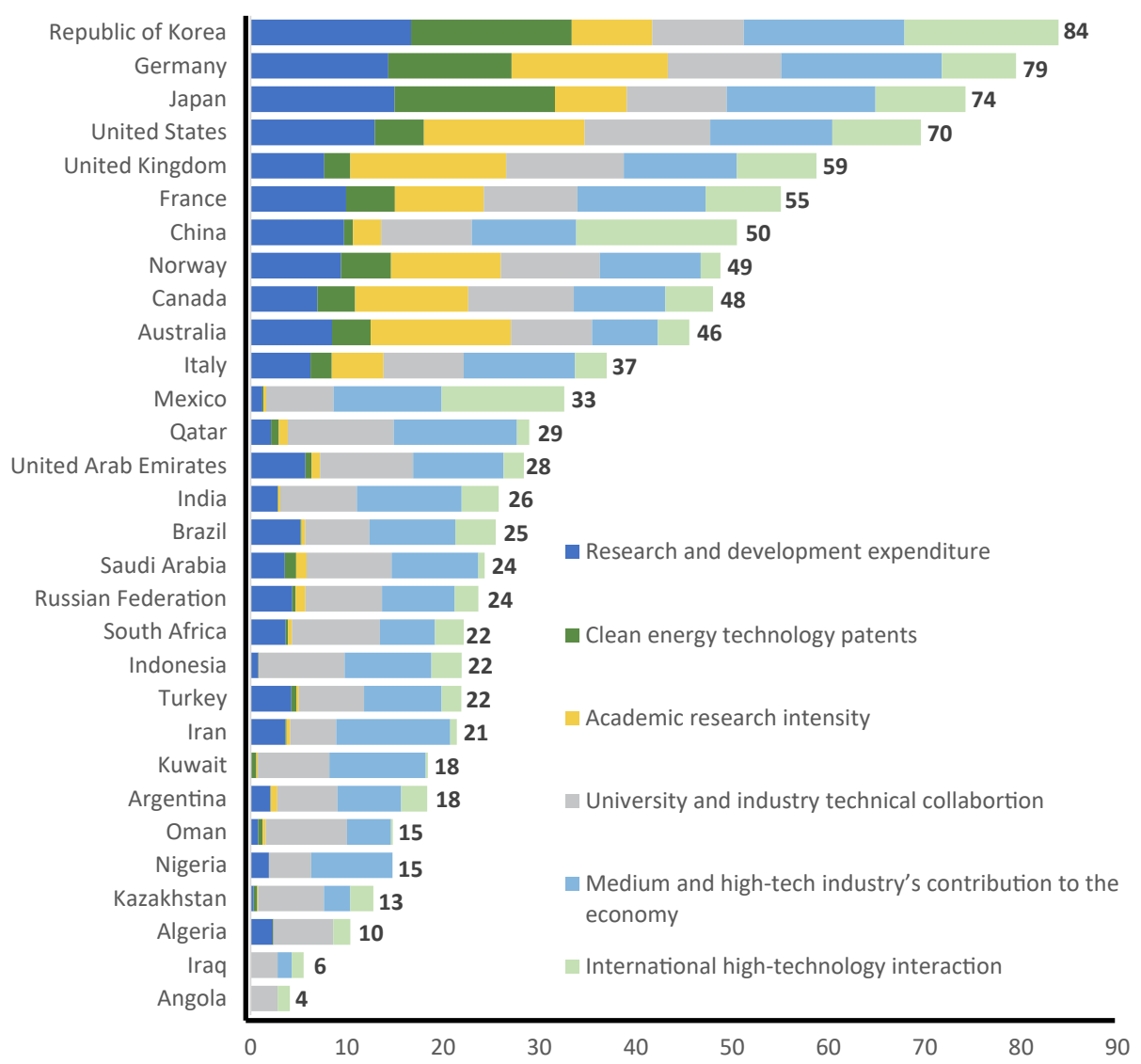

Source: Authors. 
Finance and investment indicators cover the major funding sources for sustainability projects and economic and financial instruments aimed at financing the CCE transition. Besides the importance of countries' general financial access (i.e., access to domestic and global finance), their efforts to scale up sustainable finance and investment are also crucial. The Finance and investment dimension therefore combines indicators relating to both 'conventional' and sustainable finance and investment.

The top three countries are Norway, France and the United Kingdom, and the bottom three are Iraq, Algeria and Nigeria. Despite the global sustainable investment needs estimated at multiple trillion U.S. dollars per year (OECD, UNEP and World Bank Group 2018), these flows still remain not only insufficient but also unevenly distributed: This dimension has the second largest gaps across countries (see Figure 5). A total of 17 countries score below the average (35), and the difference between the top- and bottom-three ranked country averages is a strikingly high 23.5 times (see Figure 8). The leading driver behind this immense range is countries' differential access to sustainable finance (green, social and sustainability-linked bonds and loans) and investment (public and private investment in CCErelated energy technologies). On the contrary, most countries have good or relatively good access to conventional finance (access to credit, equity and debt markets). The 30 countries under this dimension are also largely well integrated into global financial markets. In terms of economic instruments, carbon pricing (either via taxes or an emissions trading scheme) is yet to be developed or is only kickstarting in a number of countries.

Figure 8. 2021 CCE Enablers - Finance and investment sub-dimension

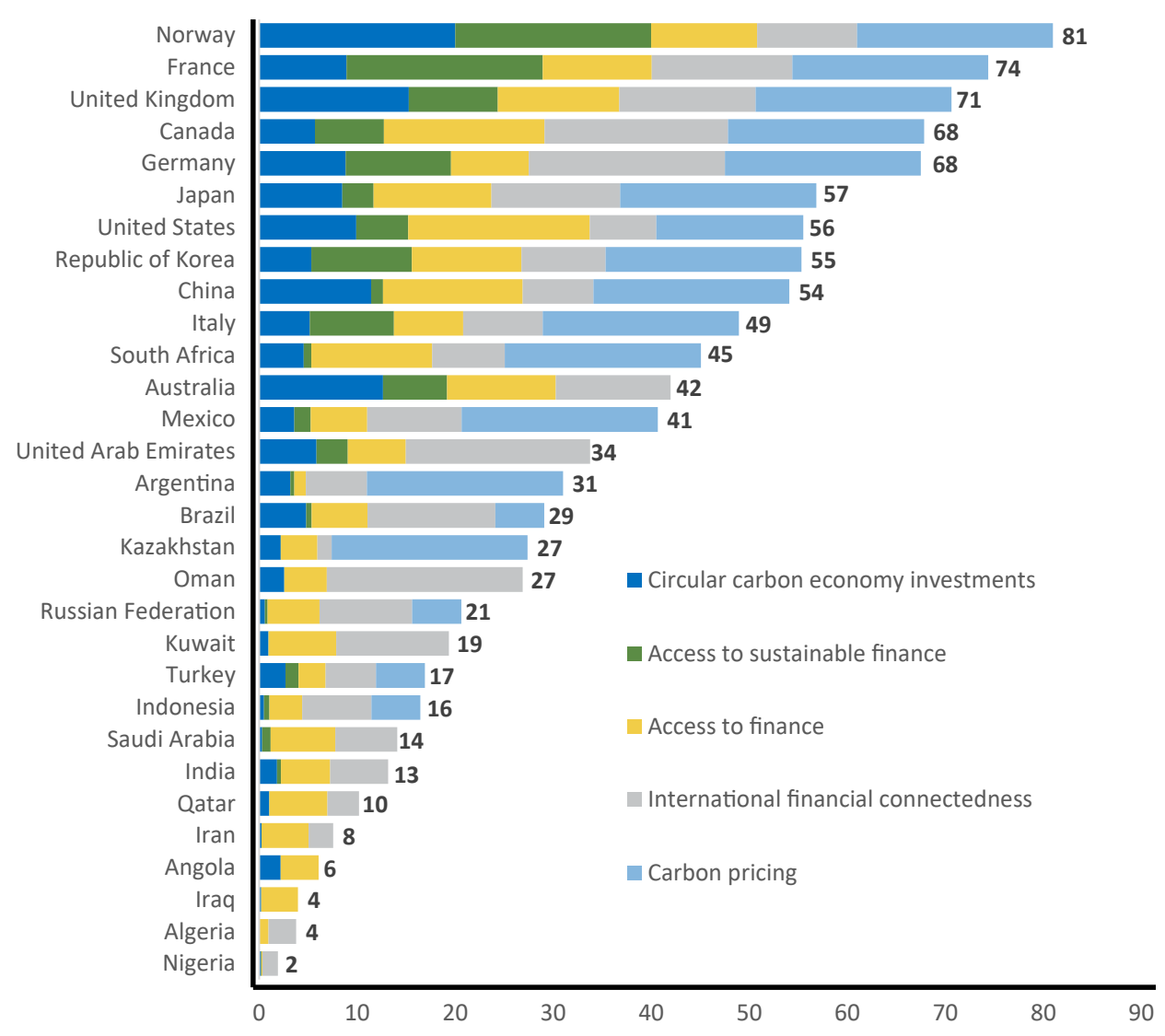

Source: Authors. 


\section{Business environment and energy security} indicators include more generic enablers covering the business climate (ease of doing business and logistics performance) and energy infrastructure (energy security and system stability), which can support and attract private actors and financing in support of CCE transitions.

Country scores for this dimension are relatively evenly distributed compared to other subdimensions (Figure 5). A smaller number of countries, 12, score below the average score (63), and the difference between the top-three and bottom-three ranked country averages is small at 2.5 times. The United States, United Kingdom and Germany sit at the top of the distribution, and Angola, Nigeria and Iraq are at the bottom. Supportive policy environment and trade and transportation infrastructure are generally strong across the countries. Energy insecurity, measured as fiscal security (i.e., the share of fuel imports of total imports of goods and services), appears a concern for only two countries: the Republic of Korea and India. Energy infrastructure instability, in turn, appears to be a challenge for Turkey, Iraq and Nigeria (see Figure 9).

Figure 9. 2021 CCE Enablers - Business environment and energy security sub-dimension

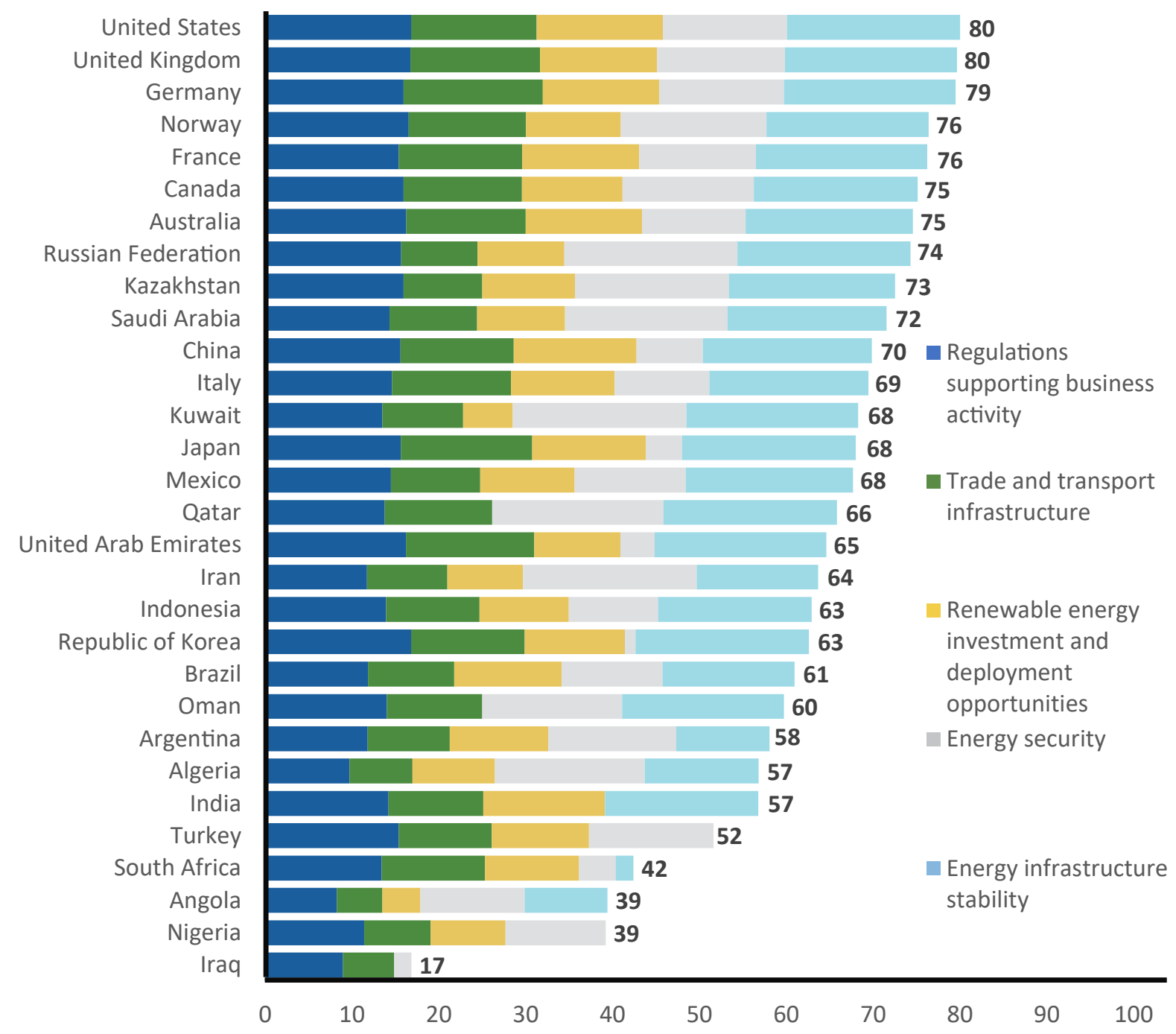

Source: Authors. 
Socioeconomic context indicators cover a set of broader social, economic and environmental enabling factors, including economic diversification, energy equity, employment, human capital productivity, environmental health, and climate change resilience, which together account for a country's general socioeconomic outlook.
The scores on this dimension do not display large variation across countries, with 13 countries scoring below the average (52). The difference between the top-three and bottom-three ranked country averages is the smallest among the five dimensions at only two times. The United Arab Emirates, Qatar and Norway are the top-three ranked countries, while South Africa, Nigeria and Iran are the bottom-three ranked countries (see Figure 10).

Figure 10. 2021 CCE Enablers - Socioeconomic context sub-dimension

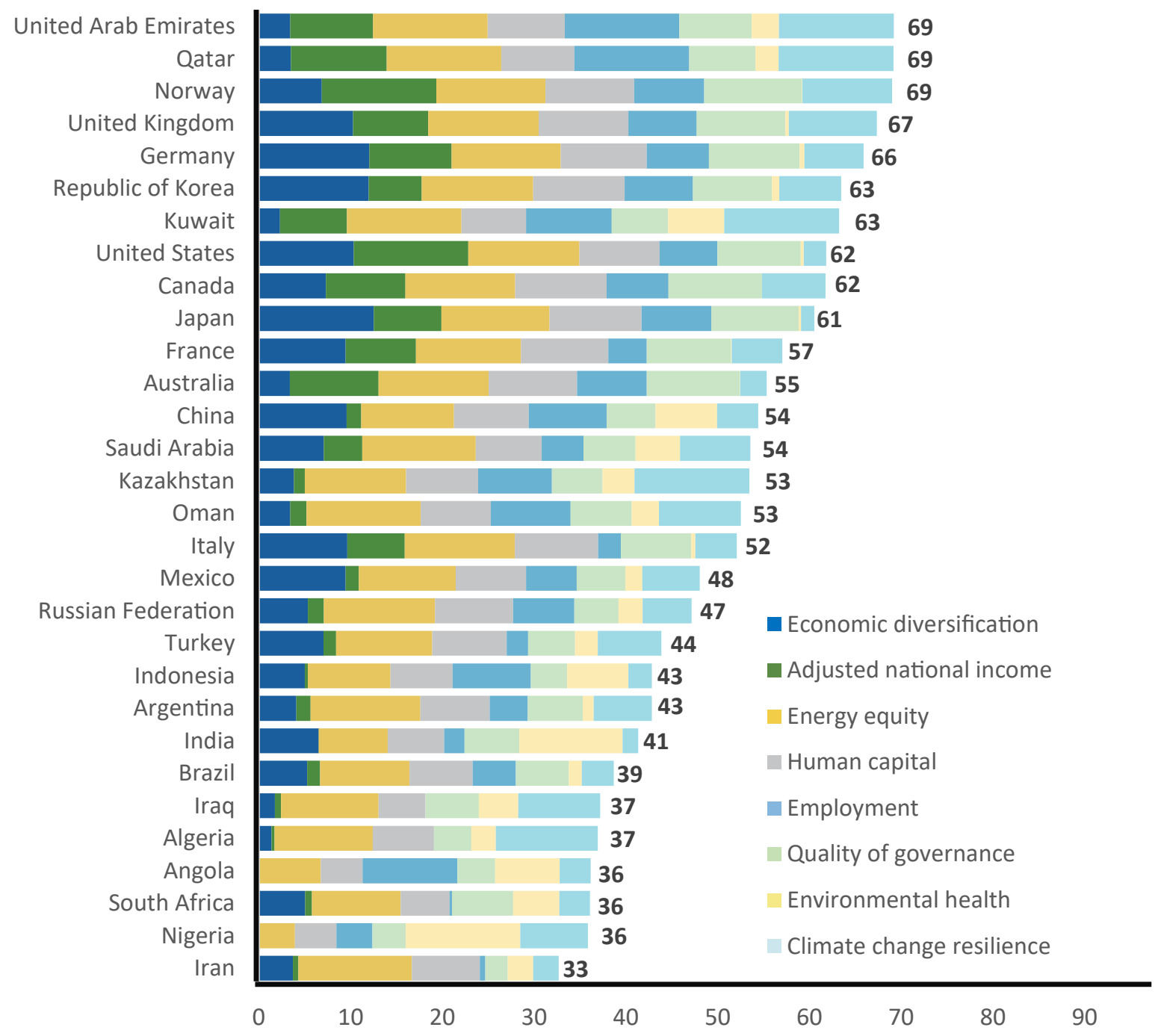

Source: Authors. 


\section{Oil Producers Lens scores}

The Oil Producers Lens (OPL) is an add-on to the CCE Index. It generates three additional scores to enable more targeted comparisons among major oil producers. The OPL total score is calculated as a simple average of the OPL Performance score and the OPL Enablers score. It is an aggregate measure of how well major oil-producing countries perform on these two dimensions (present and future) when their oil/hydrocarbon and energy-intensive sectors are factored in.

The same two countries, Norway and the United Kingdom, rank the highest on the OPL total score as on the total CCE Index score. At the other end of the scale, the same nine countries that have the lowest OPL total scores also rank the lowest on the total CCE Index scores, even if in a slightly different order. In between these extremes, there are some changes in rank when comparing the two scores (see Figure 11).

When the CCE performance and potential of the 19 countries' energy-intensive sectors are considered (through the OPL), all but one (Iraq) receive higher scores. As a result, the difference between the top and bottom performers on the OPL scores is wider than on the total CCE Index scores: Norway scores 73 on the OPL and 68 on the total CCE Index, whereas Iraq scores 20 on the OPL versus 24 on the total CCE Index. On average, countries' OPL Performance scores are slightly higher than their OPL Enablers scores, which means that the former contribute more to most countries' OPL total scores (see Figure 11).

Figure 11. 2021 Oil Producers Lens total scores and proportional sub-index contributions

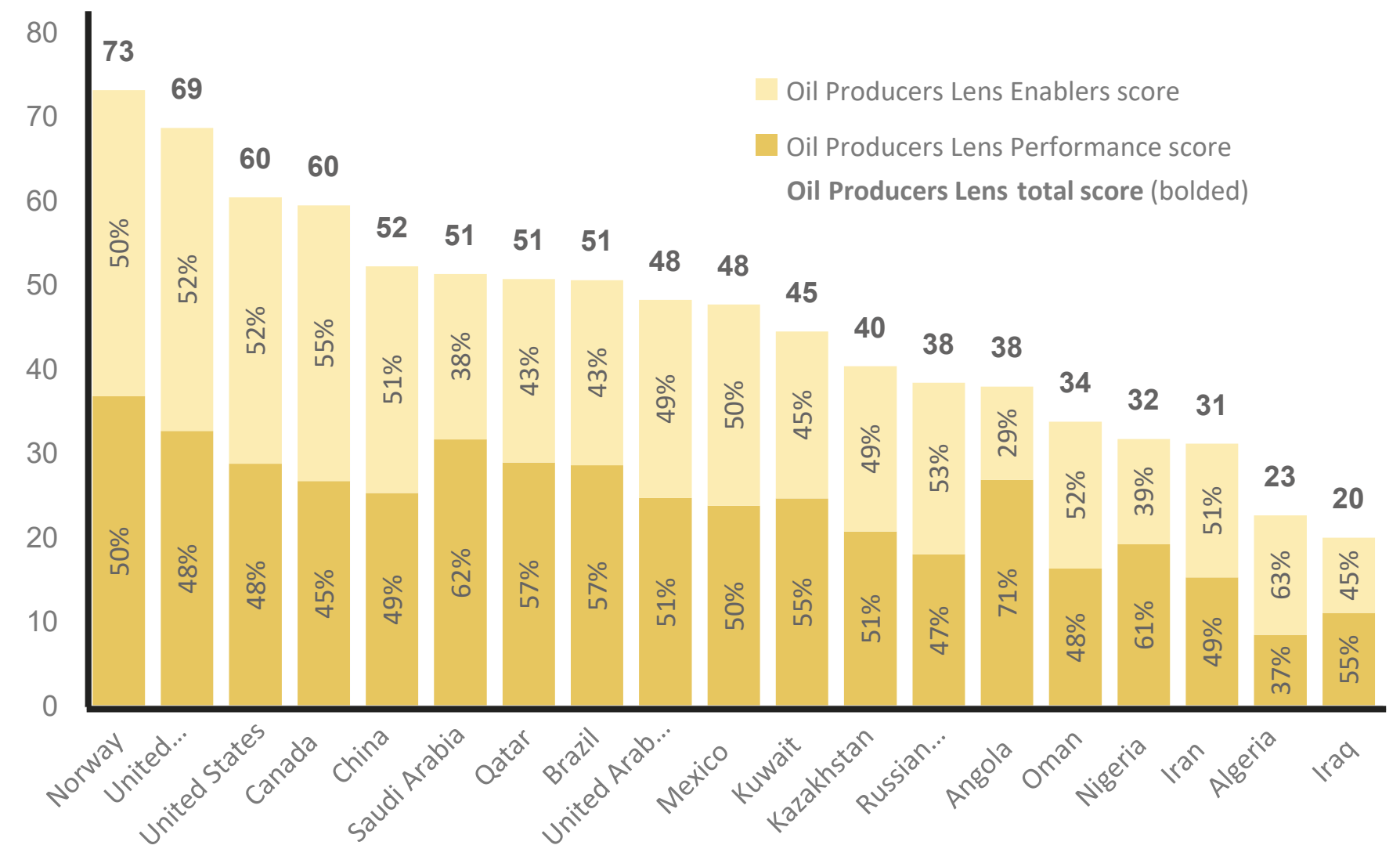

Source: Authors. 
Oil Producers Lens Performance: Both the OPL Performance and OPL Enables scores are composed of averages of the respective CCE Index sub-index scores and five OPL indicators. The OPL Performance score is a simple average of the CCE Index Performance score and the five OPL Performance indicators (see Figure 12). The 2021 OPL Performance indicators include intensity metrics aimed at measuring, on the one hand, how oil producers are managing carbon circularity in their hydrocarbon and related industries and, on the other, how efficiently they are generating value from current and future CCE assets, such as the chemicals industry. As data becomes available and carbon capture, utilization and storage applications are scaled up, future editions may include further and more direct metrics of value generation (monetizing carbon or carbon dioxide) through carbon reuse and removal.

In the 2021 edition, the top fie performers - Norway, the United Kingdom, Saudi Arabia, Qatar and the United States - all achieve high or relatively high scores on all four emissions intensity indicators, which focus on carbon dioxide and methane emissions from various parts of their energy and energy-intensive industries. In addition, two top-five performers - Saudi Arabia and Qatar - achieve high scores on the value added of the chemicals industry to the economy, which acts in the OPL as an infrastructure-based proxy toCCE value generation. ${ }^{5}$

Figure 12. 2021 Oil Producers Lens Performance scores sub-dimension

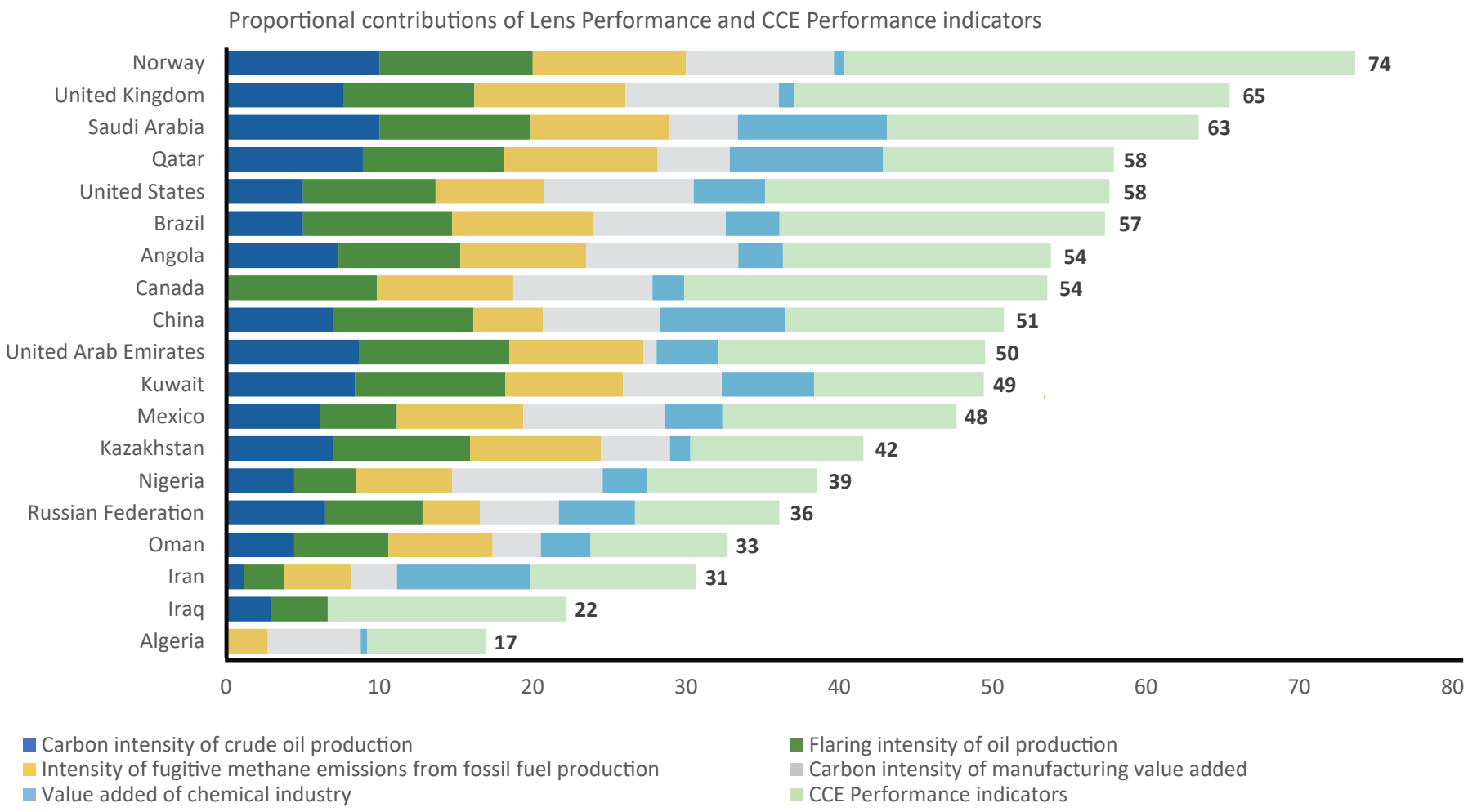

Source: Authors. 
Oil Producers Lens Enablers: The OPL Enablers score is a simple average of the five sub-dimensions of the CCE Index Enablers sub-index (which receive a $5 / 6$, or $83.33 \%$ weight in the score) and the five OPL Enablers indicators (which receive a $1 / 6$, or $16.66 \%$ weight) (for details of the weighting scheme, see Luomi, Yilmaz and Alshehri [2021]). The add-on indicators aim to measure how well the 19 countries' oil and related industries are positioned for a carbon neutral future. More specifically, the OPL Enablers indicators measure the quality of resource governance and environmental, social and governance (ESG) risks in the country, major energy and chemicals companies' sustainability reporting, a country's carbon capture and storage potential, and the government's and industry's commitment to emissions neutrality or net-zero emissions in the form of long-term targets and participation in key global partnerships.

The OPL Enablers lens does not result in major changes to the ranking among the 19 countries, compared to their relative CCE Index Enables sub-index ranking. As Figure 13 shows, countries with higher scores on OPL Enablers generally also receive higher scores across the five OPL indicators.

Figure 13. 2021 Oil Producers Lens Enablers scores

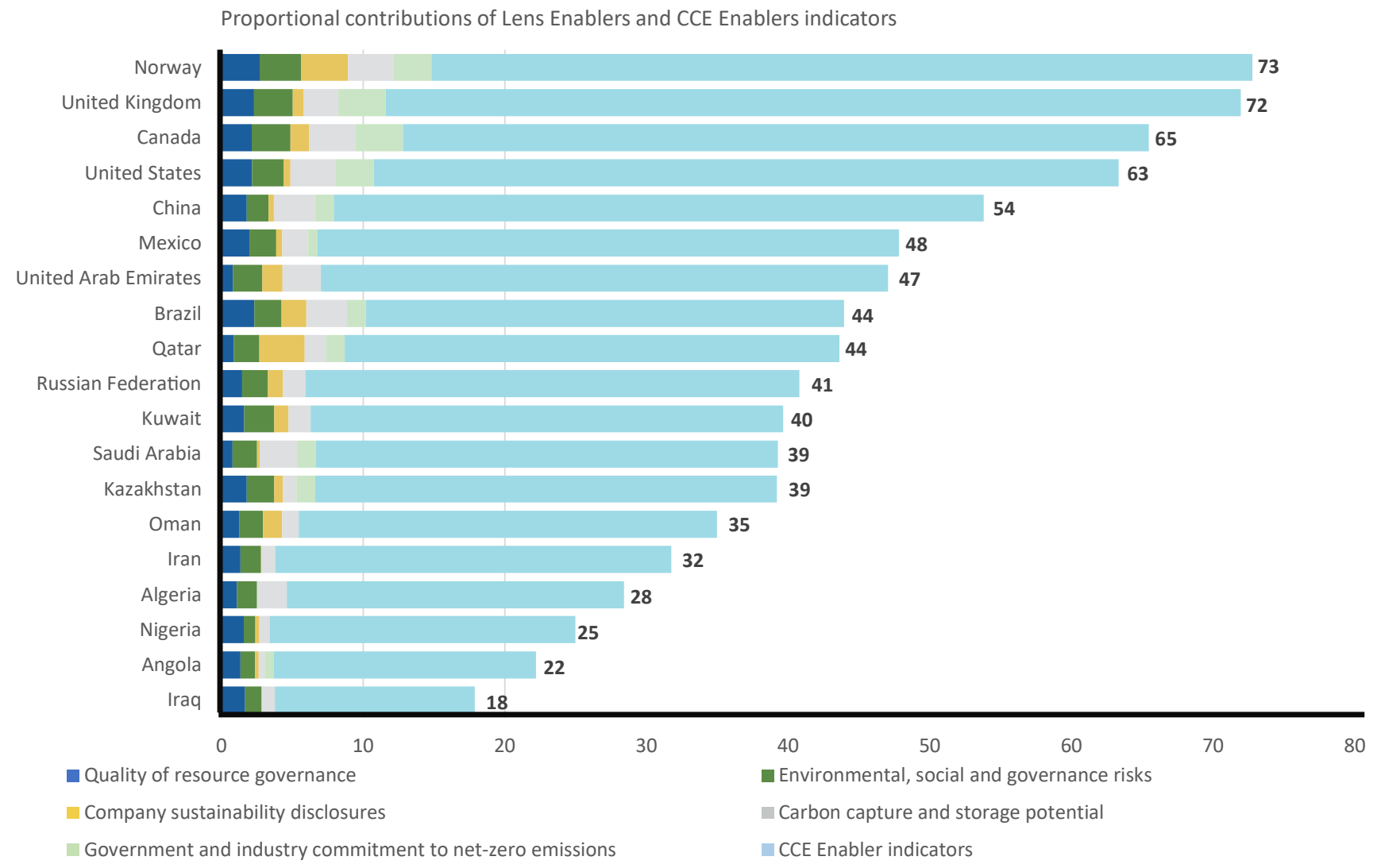

Source: Authors. 


\section{Group comparisons}

Analyzing the CCE Index results in different reference and peer groups can provide more meaningful context for policymakers. Examining countries in groups can also be useful for comparative policy discussions, as best practices and lessons learned often translate better across more homogeneous groups of countries. This section presents two ways of doing this. It examines countries in two reference groups - region and income. It also draws attention to the diversity of the Oil Producers Lens countries' economic structures. The CCE Index web portal, https://cceindex.kapsarc. org, allows for further comparisons across these different groups and among individual countries.
Regions: As shown in Figure 14, countries from Europe and Central Asia generally receive the highest scores on the 2021 CCE Index, and countries from Africa the lowest. The top-ranked countries in each region are South Africa in Africa, Canada in the Americas, Norway in Europe and Central Asia, the United Arab Emirates in the Middle East, and the Republic of Korea in South and East Asia and the Pacific. The common element across these countries appears to be their active participation in most performance and enabling factors that are crucial for progress toward CEEs. However, there are significant differences within regions.

Figure 14. Total 2021 CCE Index scores per region

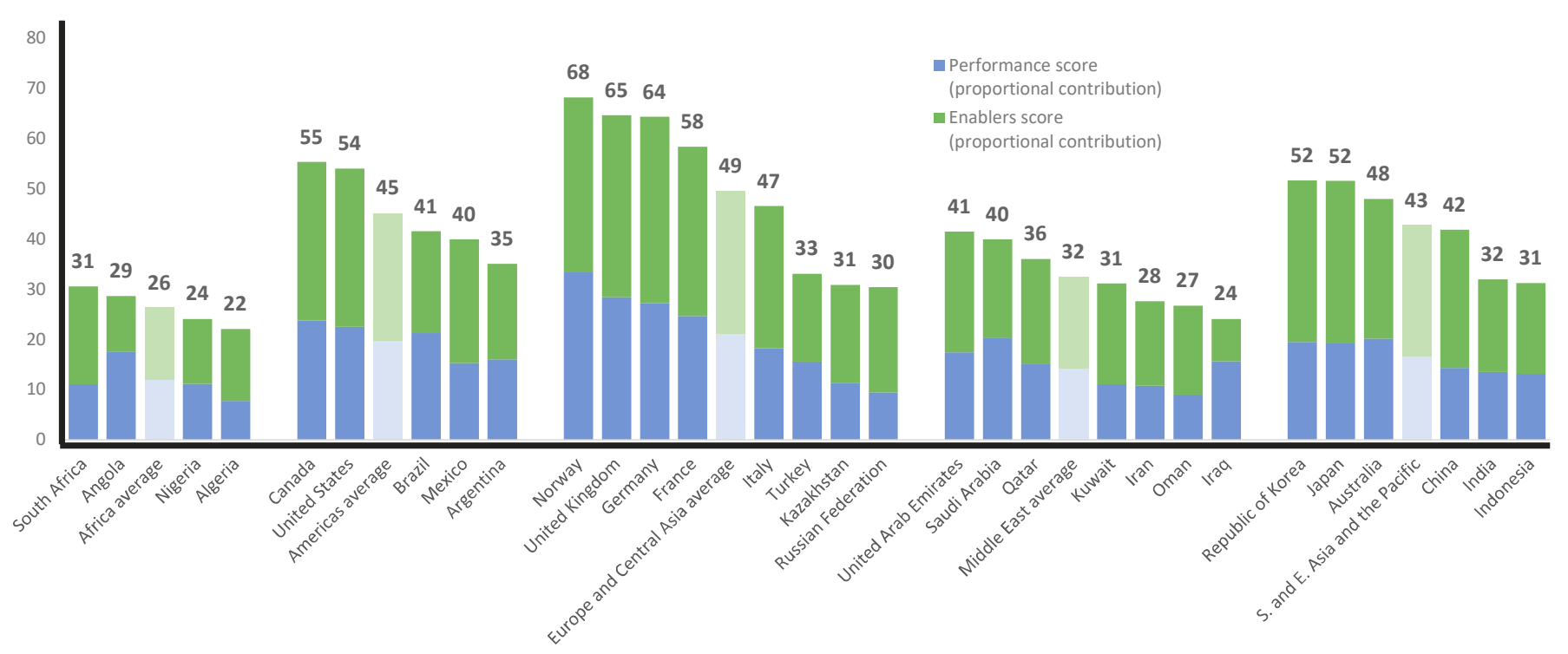

Source: Authors. 
Income: Another way to examine the CCE Index results is by segmenting countries based on their income (see Figure 15). In the high-income OECD countries' group, Norway, the United Kingdom, Germany, and France score above the group average. The United Arab Emirates, Saudi Arabia, and Qatar in turn score above the non-OECD high-income group average. China, Brazil, Mexico, Argentina, Turkey, and India score above the middle-income group average.
There appears to be some correlation between countries' income and their CCE performance. It is worth noting that while the Enablers sub-index has a sub-dimension measuring broad socioeconomic enablers, such as adjusted income and human capital, many of the more CCE-specific indicators also reflect differences in countries' socioeconomic development levels. However, income (measured by GDP per capita) only explains $62 \%$ of countries' CCE Index scores ${ }^{6}$ (for a further comparison example, see Box 3).

Figure 15. Total 2021 CCE Index scores per income group

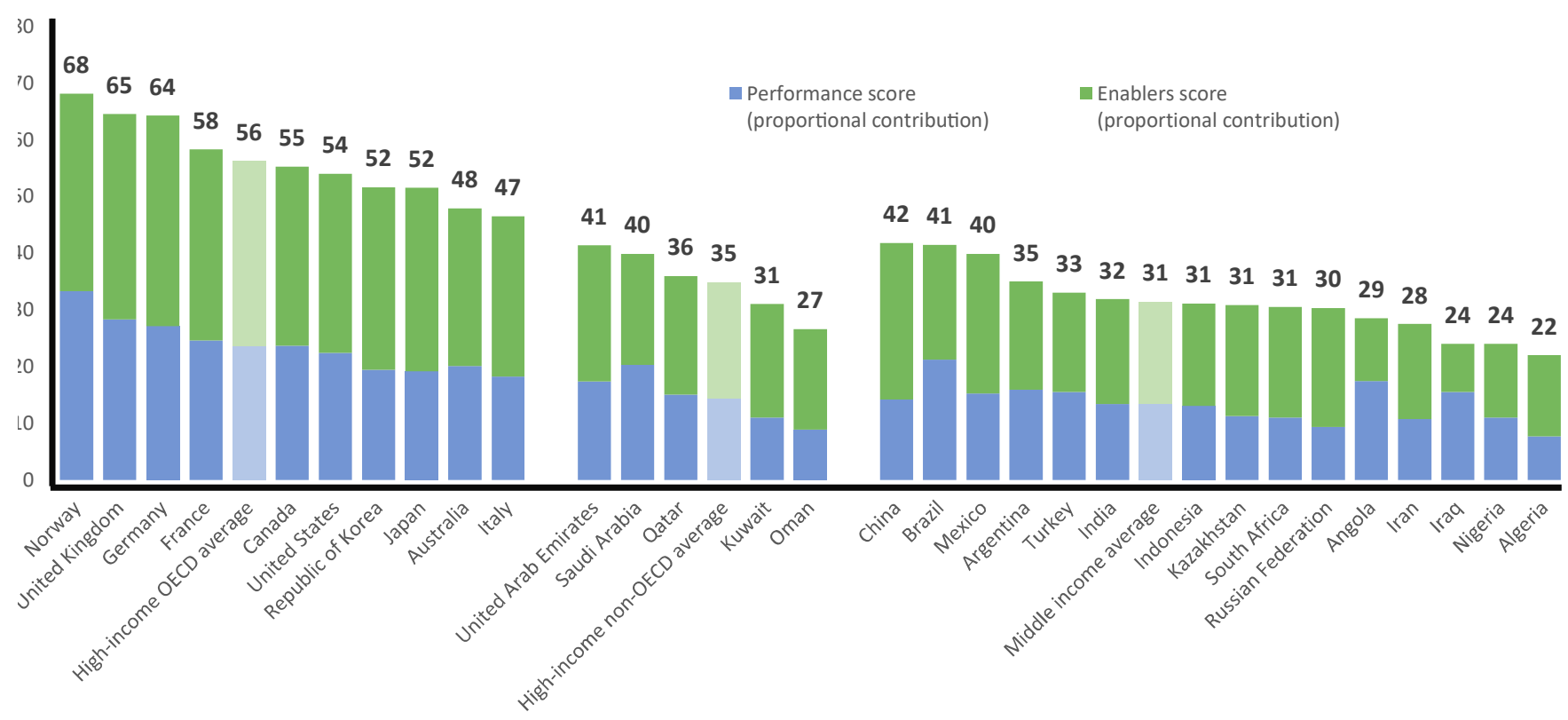

Source: Authors. 
Box 2. Comparison of the economic contribution of fuel exports and Oil Producers Lens Enablers scores

There are no direct proxy statistics for measuring how oil-producing countries are positioned vis-à-vis the CCE. However, what can be highlighted is that the scale of the coming CCE transition will vary significantly across the 19 major oil producers included in the 2021 CCE Index. For three of these countries - China, Mexico and the United Kingdom - oil and other fuel exports account for less than $10 \%$ of their merchandise exports, whereas for four countries - Algeria, Angola, Iraq and Kuwait - they account for more than $90 \%$ of these exports. If examined against the 2021 Oil Producer Lens Enablers scores, it appears that countries' potential to make progress on the CCE improves as their oil revenue dependence decreases - albeit this correlation (of $72 \%$ ) does not necessarily imply a causal relationship. The figure below displays the correlation between countries' fuel exports as a share of their merchandise exports and their 2021 Oil Producers Lens Enablers scores.

Four distinct groups of countries are distinguishable: middle-income countries with low export diversification and low CCE transition potential; higher-income countries with slightly higher export diversification and CCE transition potential; emerging economies with low reliance on fuel export revenues and relatively high CCE transition potential; and OECD countries with largely well-diversified economies and the highest CCE transition potential.

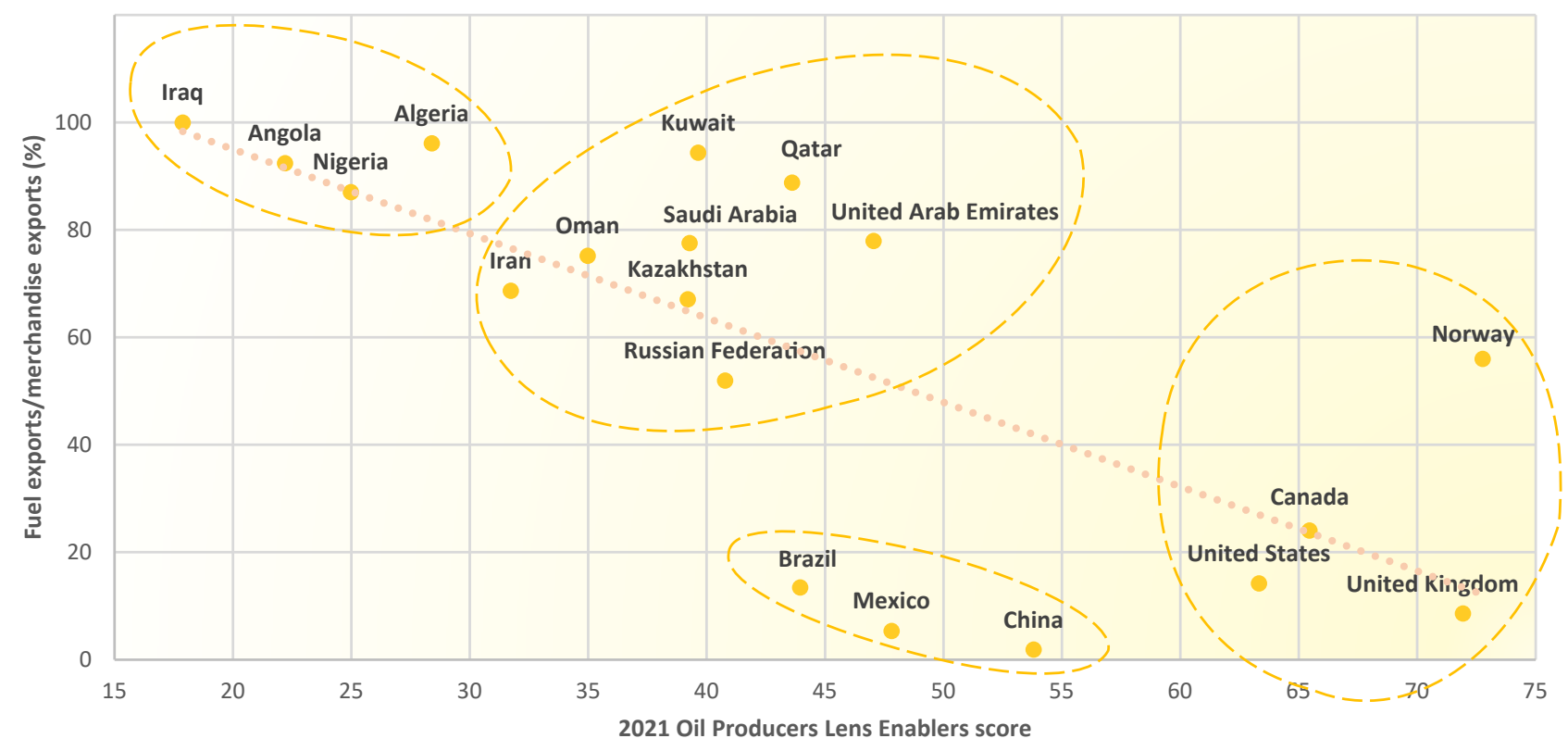

Sources: CCE Index 2021 and World Bank (2021).

Note: Fuels comprise the commodities in the Standard International Trade Classification section 3 (mineral fuels, lubricants and related materials). 


\section{Conclusion}

he CCE Index, similar to other socioeconomic composite indicators, is not only intended for ranking countries. It allows for comparisons, both in a global context and in different reference groups, but it is first and foremost intended as a tool to promote country-level, data-driven discussions on policy priorities and national strengths and weaknesses related to implementation. Close examinations of the various indicators used in the index can spur discussions to identify more appropriate CCE metrics for specific country or sub-national contexts. Gaps in data can alert data stakeholders to strive to make data available, or to develop new ways of measuring CCE performance and potential at the country level. For countries facing challenges with performance or enablers, the index can help pinpoint areas where support is needed, including from international partners.

This first edition of the CCE Index is also intended as a conversation starter for identifying the optimal ways of measuring CCE performance and enablers across countries. The CCE Index will be updated and expanded annually, and future editions will be revised to include additional countries, indicators, improved and updated datasets, and new ways of measuring CCE performance and transition enablers. The first edition of the CCE Index is therefore also put forward as an invitation to contribute to further developing this 'new language of carbon' by helping KAPSARC further refine the index to serve a growing number of countries and contexts with the best possible indicators and metrics.

We invite you to visit the CCE Index web portal to explore and compare countries and their indicator scores and values in more detail. All underlying indicator data (methodological information, sources and the original data/values) are available for viewing and downloading via the portal, https:// cceindex.kapsarc.org. 


\section{Endnotes}

${ }^{1}$ William McDonough, who originally coined the term circular carbon economy, proposed a "new language of carbon" in order "to define ways in which carbon can be used safely, productively and profitably" and which "signals positive intentions, enjoining us to do more good rather than simply be less bad" (McDonough 2016, 350).

${ }^{2}$ The target group was the top-20 oil producers, but Libya was excluded due to limited data availability (Luomi, Yilmaz and Alshehri 2021).

${ }^{3}$ In terms of the choice of years for the data as the primary option, the data for the latest available year was selected as the indicator value. Data for most indicators in the 2021 CCE Index framework are for 2018-2021. The 2021 CCE Index methodology is explained in detail in the KAPSARC Methodology Paper, "The Circular Carbon Economy Index 2021 - Methodology" (Luomi, Yilmaz and Alshehri 2021).

${ }^{4}$ Renewable energy is measured as the total share of renewables, both bio-and non-bio renewables, in total primary energy consumption. This includes modern biofuels, such as bioethanol, as well as traditional bioenergy, including firewood and charcoal. The latter are major contributors to deforestation and often have negative human health impacts. However, excluding bioenergy altogether from this indicator would penalize countries that have high rates of modern biofuel use. The index therefore uses electrification as a control variable, as countries that have high traditional bioenergy use generally have lower rates of electrification. Electrification is also a major enabler for increasing the share of renewable energy in the energy mix. The CCE Index has an indicator for fuel switching away from coal and oil as a control for these fuels in the power sector.

${ }^{5}$ For more on the link between the chemicals industry and CCE reuse applications, see IEA (2020).

${ }^{6}$ Correlations were calculated between the total CCE Index scores and GDP per capita in current US\$ at purchasing power parity for 2019 (via Enerdata [2021]). 


\section{References}

Enerdata. 2021. "Global Energy and CO2 Database." Accessed September 27, 2021. https:// www.enerdata.net/

G20 Energy Ministers. 2020. "G20 Energy Ministers Communique." September 27-28. http:// www.g20.utoronto.ca/2020/G20SS_Energy_ Ministers_Meeting_Communique.pdf

International Energy Agency (IEA). 2020. "Reuse: Carbon Reuse. G20 Circular Carbon Economy Guide Report." August. https://www.cceguide.org/ guide/

KAPSARC. 2020. "CCE Guide: Overview. A guide to the circular carbon economy (CCE)." https://www.cceguide.org/guide/

Luomi, Mari, Fatih Yilmaz, and Thamir Alshehri. 2021. "The Circular Carbon Economy Index 2021 - Methodology." KAPSARC Methodology Paper. https://doi.org/10.30573/KS--2021-MP02

Luomi, Mari, Fatih Yilmaz, Thamir Alshehri, and Nicholas Howarth. 2021. "The Circular Carbon Economy Index - Methodological Approach and Conceptual Framework." KAPSARC Methodology Paper. May. https://doi.org/10.30573/

KS--2021-MP01
McDonough, William. 2016. "Carbon is not the enemy." Nature, no. 539 (November 17): 349-351. https://doi.org/10.1038/539349a

Organisation for Economic Co-operation and Development (OECD), United Nations Environment Programme (UNEP) and World Bank Group. 2018. "Financing Climate Futures: Rethinking Infrastructure. Policy Highlights." Published under the responsibility of the Secretary-General of the OECD. https://www.oecd.org/environment/cc/ climate-futures/policy-highlights-financing-climatefutures.pdf

United Nations Framework Convention on Climate Change (UNFCCC). 2015. "Adoption of the Paris Agreement. Decision 1/CP.21. FCCC/CP/2015/10/ Add.1." https://unfccc.int/resource/docs/2015/cop21/ eng/10a01.pdf

World Bank. 2021. "Fuel exports (\% of merchandise exports)." Accessed September 27, 2021. https:// data.worldbank.org/indicator/TX.VAL.FUEL.ZS.UN 


\section{Appendix 1: 2021 CCE Index results}

The tables in this appendix contain the scores and ranks for the CCE Index, the Performance sub-index, the Enablers sub-index and its subdimensions, and the Oil Producers Lens. Underlying data (original values) and scores for all 47 indicators included in the 2021 CCE Index are available for download via the CCE Index web portal. The values and scores are also available in an interactive form on the CCE Index web portal, https://cceindex. kapsarc.org.

2021 CCE Index scores and rankings

\begin{tabular}{|c|c|c|c|c|c|c|c|c|c|c|c|c|c|c|c|c|}
\hline & \multicolumn{2}{|c|}{ CCE Index } & \multicolumn{2}{|c|}{$\begin{array}{l}\text { Performance } \\
\text { sub-index }\end{array}$} & \multicolumn{2}{|c|}{$\begin{array}{l}\text { Enablers } \\
\text { sub-index }\end{array}$} & \multicolumn{2}{|c|}{$\begin{array}{c}\text { Policies } \\
\text { and regulation } \\
\text { dimension }\end{array}$} & \multicolumn{2}{|c|}{$\begin{array}{l}\text { Technology, } \\
\text { knowledge } \\
\text { and innovation } \\
\text { dimension }\end{array}$} & \multicolumn{2}{|c|}{$\begin{array}{c}\text { Finance and } \\
\text { investment } \\
\text { dimension }\end{array}$} & \multicolumn{2}{|c|}{$\begin{array}{c}\text { Business } \\
\text { environment \& } \\
\text { energy security } \\
\text { dimension }\end{array}$} & \multicolumn{2}{|c|}{$\begin{array}{c}\text { Socioeconomic } \\
\text { context } \\
\text { dimension }\end{array}$} \\
\hline & ֻे & 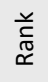 & ๗ัँ & 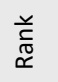 & ڤัँ & 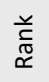 & ๗ัু & 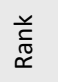 & ๗ัँ & 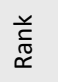 & ๗ัँ & 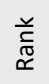 & ญั & 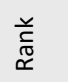 & ญัँ & 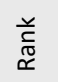 \\
\hline Norway & 68.09 & 1 & 66.63 & 1 & 69.55 & 3 & 72.63 & 5 & 48.79 & 8 & 80.99 & 1 & 76.36 & 4 & 68.98 & 3 \\
\hline United Kingdom & 64.57 & 2 & 56.74 & 2 & 72.41 & 2 & 85.66 & 1 & 58.75 & 5 & 70.64 & 3 & 79.65 & 2 & 67.33 & 4 \\
\hline Germany & 64.26 & 3 & 54.31 & 3 & 74.21 & 1 & 78.72 & 2 & 79.47 & 2 & 67.52 & 5 & 79.47 & 3 & 65.89 & 5 \\
\hline France & 58.32 & 4 & 49.21 & 4 & 67.43 & 4 & 74.44 & 4 & 55.07 & 6 & 74.39 & 2 & 76.22 & 5 & 57.03 & 11 \\
\hline Canada & 55.29 & 5 & 47.40 & 5 & 63.19 & 7 & 63.27 & 7 & 48.00 & 9 & 67.84 & 4 & 75.09 & 6 & 61.74 & 9 \\
\hline United States & 54.00 & 6 & 44.89 & 6 & 63.10 & 8 & 48.62 & 12 & 69.60 & 4 & 55.51 & 7 & 79.98 & 1 & 61.81 & 8 \\
\hline Republic of Korea & 51.62 & 7 & 38.84 & 10 & 64.41 & 6 & 56.80 & 10 & 83.89 & 1 & 55.33 & 8 & 62.60 & 20 & 63.42 & 6 \\
\hline Japan & 51.52 & 8 & 38.36 & 11 & 64.68 & 5 & 63.86 & 6 & 74.21 & 3 & 56.85 & 6 & 67.97 & 14 & 60.52 & 10 \\
\hline Australia & 47.92 & 9 & 40.23 & 9 & 55.62 & 10 & 60.66 & 8 & 45.55 & 10 & 41.99 & 12 & 74.56 & 7 & 55.32 & 12 \\
\hline Italy & 46.50 & 10 & 36.45 & 12 & 56.56 & 9 & 75.36 & 3 & 36.99 & 11 & 48.94 & 10 & 69.44 & 12 & 52.09 & 17 \\
\hline China & 41.76 & 11 & 28.47 & 20 & 55.05 & 11 & 46.40 & 15 & 50.49 & 7 & 54.10 & 9 & 69.85 & 11 & 54.39 & 13 \\
\hline Brazil & 41.48 & 12 & 42.45 & 7 & 40.51 & 16 & 48.41 & 13 & 25.44 & 16 & 29.09 & 16 & 60.94 & 21 & 38.68 & 24 \\
\hline United Arab Emirates & 41.44 & 13 & 34.83 & 14 & 48.04 & 13 & 44.31 & 16 & 28.37 & 14 & 33.76 & 14 & 64.61 & 17 & 69.18 & 1 \\
\hline Mexico & 39.91 & 14 & 30.55 & 18 & 49.27 & 12 & 57.43 & 9 & 32.57 & 12 & 40.67 & 13 & 67.66 & 15 & 48.03 & 18 \\
\hline Saudi Arabia & 39.88 & 15 & 40.63 & 8 & 39.13 & 18 & 32.19 & 25 & 24.30 & 17 & 14.10 & 23 & 71.51 & 10 & 53.57 & 14 \\
\hline Qatar & 35.99 & 16 & 30.10 & 19 & 41.88 & 14 & 35.29 & 23 & 28.94 & 13 & 10.19 & 25 & 65.83 & 16 & 69.14 & 2 \\
\hline Argentina & 35.00 & 17 & 31.94 & 15 & 38.05 & 21 & 40.10 & 20 & 18.33 & 24 & 31.00 & 15 & 58.04 & 23 & 42.79 & 22 \\
\hline Turkey & 33.06 & 18 & 31.01 & 17 & 35.11 & 25 & 41.29 & 19 & 21.89 & 21 & 16.91 & 21 & 51.58 & 26 & 43.87 & 20 \\
\hline India & 31.90 & 19 & 26.86 & 21 & 36.94 & 22 & 47.71 & 14 & 25.77 & 15 & 13.16 & 24 & 56.75 & 25 & 41.31 & 23 \\
\hline Indonesia & 31.14 & 20 & 26.11 & 22 & 36.18 & 23 & 36.82 & 22 & 21.91 & 20 & 16.44 & 22 & 62.92 & 19 & 42.81 & 21 \\
\hline Kuwait & 31.06 & 21 & 22.11 & 25 & 40.01 & 17 & 30.80 & 26 & 18.40 & 23 & 19.36 & 20 & 68.27 & 13 & 63.20 & 7 \\
\hline Kazakhstan & 30.84 & 22 & 22.58 & 23 & 39.10 & 19 & 29.43 & 27 & 12.76 & 27 & 27.39 & 17 & 72.50 & 9 & 53.43 & 15 \\
\hline South Africa & 30.51 & 23 & 22.08 & 26 & 38.95 & 20 & 49.04 & 11 & 22.14 & 19 & 45.07 & 11 & 42.40 & 27 & 36.09 & 28 \\
\hline Russian Federation & 30.34 & 24 & 18.85 & 28 & 41.84 & 15 & 43.50 & 17 & 23.65 & 18 & 20.62 & 19 & 74.29 & 8 & 47.14 & 19 \\
\hline Angola & 28.57 & 25 & 34.95 & 13 & 22.20 & 29 & 25.34 & 28 & 4.07 & 30 & 6.05 & 27 & 39.41 & 28 & 36.14 & 27 \\
\hline Iran & 27.54 & 26 & 21.55 & 27 & 33.52 & 26 & 42.36 & 18 & 21.41 & 22 & 7.54 & 26 & 63.65 & 18 & 32.65 & 30 \\
\hline Oman & 26.65 & 27 & 17.86 & 29 & 35.44 & 24 & 23.30 & 29 & 14.77 & 25 & 26.90 & 18 & 59.71 & 22 & 52.51 & 16 \\
\hline Iraq & 24.05 & 28 & 31.16 & 16 & 16.94 & 30 & 21.24 & 30 & 5.53 & 29 & 3.94 & 28 & 16.84 & 30 & 37.17 & 25 \\
\hline Nigeria & 24.03 & 29 & 22.17 & 24 & 25.90 & 28 & 37.79 & 21 & 14.74 & 26 & 1.91 & 30 & 39.20 & 29 & 35.85 & 29 \\
\hline Algeria & 22.02 & 30 & 15.49 & 30 & 28.55 & 27 & 34.91 & 24 & 10.36 & 28 & 3.77 & 29 & 56.78 & 24 & 36.93 & 26 \\
\hline
\end{tabular}

Source: Authors. 
2021 CCE Index scores and rankings - Oil Producers Lens

\begin{tabular}{|c|c|c|c|c|c|c|c|c|c|c|}
\hline & \multicolumn{2}{|c|}{$\begin{array}{c}\text { Oil Producers } \\
\text { Lens } \\
\text { total score }\end{array}$} & \multicolumn{2}{|c|}{$\begin{array}{c}\text { Oil Producers } \\
\text { Lens } \\
\text { Performance } \\
\text { score }\end{array}$} & \multicolumn{2}{|c|}{$\begin{array}{l}\text { Oil Producers Lens } \\
\text { Performance } \\
\text { indicators average }\end{array}$} & \multicolumn{2}{|c|}{$\begin{array}{l}\text { Oil Producers } \\
\text { Lens } \\
\text { Enablers score }\end{array}$} & \multicolumn{2}{|c|}{$\begin{array}{c}\text { Oil Producers Lens } \\
\text { Enablers indicators } \\
\text { average }\end{array}$} \\
\hline & ֻั & 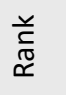 & ๖ัّ & 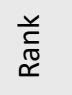 & ๖ัँ & 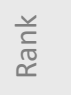 & ֻั & 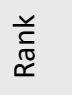 & џั & 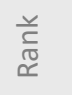 \\
\hline Norway & 73.21 & 1 & 73.65 & 1 & 80.67 & 3 & 72.76 & 1 & 88.81 & 1 \\
\hline United Kingdom & 68.69 & 2 & 65.46 & 2 & 74.17 & 5 & 71.93 & 2 & 69.54 & 3 \\
\hline United States & 60.47 & 3 & 57.62 & 5 & 70.34 & 9 & 63.32 & 4 & 64.39 & 4 \\
\hline Canada & 59.51 & 4 & 53.57 & 8 & 59.74 & 13 & 65.45 & 3 & 76.76 & 2 \\
\hline China & 52.26 & 5 & 50.72 & 9 & 72.98 & 6 & 53.80 & 5 & 47.59 & 7 \\
\hline Saudi Arabia & 51.35 & 6 & 63.43 & 3 & 86.24 & 1 & 39.28 & 12 & 39.99 & 10 \\
\hline Qatar & 50.75 & 7 & 57.90 & 4 & 85.70 & 2 & 43.60 & 9 & 52.22 & 6 \\
\hline Brazil & 50.63 & 8 & 57.32 & 6 & 72.19 & 8 & 43.94 & 8 & 61.11 & 5 \\
\hline United Arab Emirates & 48.28 & 9 & 49.50 & 10 & 64.18 & 11 & 47.05 & 7 & 42.06 & 8 \\
\hline Mexico & 47.73 & 10 & 47.64 & 12 & 64.74 & 10 & 47.81 & 6 & 40.51 & 9 \\
\hline Kuwait & 44.53 & 11 & 49.42 & 11 & 76.74 & 4 & 39.64 & 11 & 37.81 & 12 \\
\hline Kazakhstan & 40.39 & 12 & 41.57 & 13 & 60.57 & 12 & 39.20 & 13 & 39.69 & 11 \\
\hline Russian Federation & 38.44 & 13 & 36.09 & 15 & 53.33 & 15 & 40.78 & 10 & 35.49 & 13 \\
\hline Angola & 37.99 & 14 & 53.79 & 7 & 72.63 & 7 & 22.20 & 18 & 22.17 & 18 \\
\hline Oman & 33.84 & 15 & 32.70 & 16 & 47.54 & 16 & 34.97 & 14 & 32.65 & 14 \\
\hline Nigeria & 31.77 & 16 & 38.55 & 14 & 54.94 & 14 & 24.98 & 17 & 20.37 & 19 \\
\hline Iran & 31.19 & 17 & 30.64 & 17 & 39.73 & 17 & 31.73 & 15 & 22.77 & 16 \\
\hline Algeria & 22.68 & 18 & 16.96 & 19 & 18.43 & 18 & 28.39 & 16 & 27.61 & 15 \\
\hline Iraq & 20.04 & 19 & 22.21 & 18 & 13.25 & 19 & 17.88 & 19 & 22.56 & 17 \\
\hline
\end{tabular}

Source: Authors. 


\section{About the Authors}

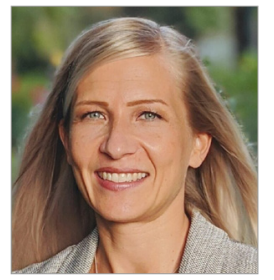

\section{Mari Luomi}

Mari is a policy-oriented social scientist who has been studying climate change, energy transitions and sustainable development policy in the Gulf and globally for close to 15 years. She has worked for other leading energy, sustainable development and foreign policy research institutions, including the Oxford Institute for Energy Studies, the International Institute for Sustainable Development (Earth Negotiations Bulletin), Georgetown University, the Finnish Institute of International Affairs, and the Emirates Diplomatic Academy.

Mari holds a master's degree in political science and international politics from the University of Helsinki and a Ph.D. in Middle Eastern Studies from Durham University. In addition to a broad research publications portfolio, she has substantial experience in executive training, presentations, policy advisory, and reporting services for multilateral environmental negotiations.

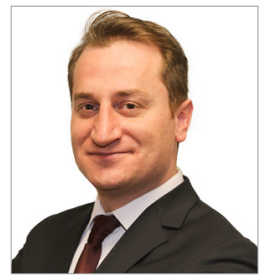

\section{Fatih Yilmaz}

Fatih is a senior research associate in the Energy Transitions and Electric Power program. His current research agenda aims to enhance our understanding of the financial and economic consequences of the global energy transition toward renewables, and to design effective policies to balance financial risks and growth prospects.

Before joining KAPSARC, Fatih worked as an economist at the Structural Economic Research Department of the Central Bank of the Republic of Turkey, where he was involved in research and designing policies for the real and financial sectors. He has worked as a consultant for the World Bank and spent a year as an assistant professor of economics at the ADA University. He has authored various academic and policy articles and helped to organize conferences and workshops. He holds a Ph.D. in economics from the University of Calgary. 


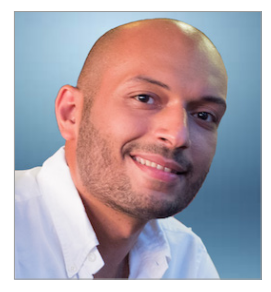

\section{Thamir Alshehri}

Thamir is a research associate in the Energy Transitions and Electric Power program. $\mathrm{He}$ is currently focused on creating data-driven tools to identify and evaluate different energy market scenarios, as well as using 'big data' technologies to better understand the impact of consumer behavior and the environment on energy consumption. Thamir is interested in using technologies to facilitate better energy public policy and energy economical systems.

Thamir also acts as an advisor to the broader energy ecosystem in Saudi Arabia, particularly in the areas of clean energy transitions, sustainability, and carbon emissions management. He is also a member of the Technology and Economic Assessment Panel, United Nations Environment Programme (UNEP).

He previously worked as a lecturer in Australia and has entrepreneurial and industrial experience working on award-winning projects such as the Burj Khalifah Building Management System.

\section{About the Project}

The Circular Carbon Economy (CCE) Index project seeks to expand and add rigor to the conceptual basis of the concept of the CCE, as well as its practical operationalization, by developing a robust quantitative framework for measuring countries' performance and progress toward CCEs. The resulting CCE Index is a composite indicator that measures various dimensions of the CCE in a national context across countries. Its main foci are current performance and enabling factors for future progress.

The project consists of various components, including a consultation paper published in June 2021, which provided a preliminary conceptual-methodological framework for the CCE Index and was used by the index team to support related expert and stakeholder consultations. The CCE Index also convened its International Technical Advisory Committee, with five initial members, to help improve the robustness of the index methodology.

This first edition of the CCE Index covers 30 major economies and oil-producing countries. It is being disseminated through various research outputs, including this discussion paper, a methodology paper presenting the 2021 CCE Index methodology, and an online platform, located at https://cceindex.kapsarc.org.

The CCE Index has two main functions: first, it is intended to enable further discussions around ways to identify, measure and compare countries' strengths and weaknesses in terms of the CCE, and to help pinpoint areas where progress is already well underway and where further policy efforts are needed or could be beneficial. Second, the index promotes the further understanding of the CCE concept and the overall idea of adopting a holistic approach to managing emissions across energy systems and economies and achieving carbon circularity. The project also seeks to support discussions within Saudi Arabia, and other interested countries, on ways to measure and advance toward CCEs. 
INAPSARC

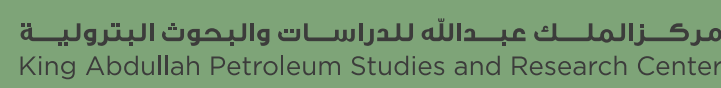

www.kapsarc.org 